\title{
Characterization of Lipids in Femoral Atheroma from Diabetic Patients and Their Use as Clinical Descriptors
}

\author{
Mónica Narváez-Rivas ${ }^{1}$, Iza-Fernanda Pérez-Ramírez², Emerenciana Gallardo¹, José Luis González-Peña ${ }^{3}$, Javier Juárez-Becerra ${ }^{4}$ and \\ Manuel León-Camacho ${ }^{1^{*}}$
}

${ }^{1}$ Lipid Characterization and Quality Department, Instituto de la Grasa (C.S.I.C.) Ctra Utrera km 1, Campus Universitario Pablo de Olavide, Spain ${ }^{2}$ Departamento de Bromatología y Nutrición, Universidad Autónoma de Tamaulipas, UAM Reynosa-Aztlán, México

${ }^{3}$ Department of Cardiology, Christus Mugerza Hospital, Reynosa, Tamaulipas, Mexico4Department of Angiology and Vascular Surgery, Regional de PEMEX Hospital, Reynosa, Tamaulipas, México

\begin{abstract}
In this work, a solid phase extraction (SPE) method is used to separate the different lipid fractions of atheroma plaque from diabetic human patients for their subsequent analysis. Sixteen fatty acids, seventeen triacylglycerols, eleven diacylglycerols being each of them as 1,2- and 1,3-isomers, two free fatty acids, 1-monoolein and seven phospholipid classes were identified. The discriminating power of the different compounds characterized has been studied in order to use them as clinical descriptor. Linear Discriminant Analysis has been applied for such purposed, diacylglycerols being the most useful compounds giving models with a total classification when sex, dyslipidemia, heart attack and stage of atheroma from patients were considered. This methodology has been used to highlight the differences between sex and age of the patients, as well as to find out differences between patients with different diseases such as dyslipidemia, heart attack, metabolic syndrome and renal failure.
\end{abstract}

Keywords: Atheroma plaque; Diabetes mellitus; Dyslipidemia; Lipids; SPE; Pattern recognition techniques

\section{Introduction}

Atherosclerosis is a chronic disease that develops gradually over a lifetime, but it presents clinical manifestations only after four or five decades of silent progression and it is characterized by the extensive accumulation of lipids in the subendothelial matrix, leading to an inflammatory response, which together forms the basic lesion of the disease, the atherosclerotic plaque [1]. Atherosclerosis is the main cause of circulatory system disease, which is the first cause of mortality in the world, contributing with $29 \%$ of the deaths and includes coronary heart disease, cerebrovascular disease and peripheral arterial disease [2]. This also is the main cause of death in patients with type I and II diabetes mellitus, contributing with $80 \%$ of all deaths and $75 \%$ of hospitalizations [3]. Atherosclerotic lesions present a selective distribution, being primarily found in medium and large caliber arteries located mainly in flow division zones, regions where the blood flow characteristics increase the molecules deposit within the arterial wall [4]. The pathogenesis of atherosclerosis involves a complex interplay of lipid abnormalities, oxidative stress, inflammation and thrombogenicity that lead to clinical sequelae. Traditional risk factors, such as diabetes mellitus hyperlipidemia and hypertension, are well accepted in contributing to atherosclerosis $[5,6]$.

Atheroma plaques are found in different regions like heart, brain, and extremities simultaneously but at different stages of development. Usually they are settled in the arteries that irrigate the heart (coronaries), the brain (carotids, vertebrals and cerebrals) and lower-extremities (iliacs and femorals) [7]. Several studies have shown that chemical composition, rather than anatomy, determine atheroma plaque instability and predict either disease progression or regression $[8,9]$. Accumulation of lipids in atheroma plaque causes progressive narrowing of the arterial lumen, often followed by thrombosis and ischemia. The lipid composition of the plaque is determined by chemical analysis of completely disrupted plaques [10-13].

The lipid composition of atheroma plaque has been extensively investigated in experimental animal models and in the human, although nowadays there is a renewed interest in the study of plaque lipid composition because it is recognized that it, rather than the luminal narrowing, influences the plaque stability and determines patient symptoms [9,14-21]. According to the review of Lee et al. [22], there is increasing clinical evidence that phospholipid (PL) oxidation products play a role in atherosclerosis and promote phenotypic changes in endothelial cell that have long-term consequences for the vessel wall. The most important components present in the plaque are total cholesterol, esters of cholesterol and PLs [23]. According to Felton et al. [24], PLs represent $6.2-8.1 \mathrm{mg} / \mathrm{g}$ of total lipids in tissue (14\% of plaque lipid). Irrespective of plaque type, the average concentrations of phospholipid saturated fatty acids (SFAs), monounsaturated fatty fatty acids (MUFAs), and total polyunsaturated fatty acids (PUFAs) were $2.5,1.0$, and $1.5 \mathrm{mg} / \mathrm{g}$, respectively. Besides, SFAs, MUFAs, and PUFAs represented $50 \%, 20 \%$, and $30 \%$ of fatty acids, respectively, independently of the kind of plaque [24].

Taking into account that lipids, abundant constituents of both the vascular plaque and lipoproteins, play a pivotal role in atherosclerosis [25], a solid phase extraction (SPE) method to separate the different lipid fractions is proposed in the present article concretely and the use of them as clinical descriptors, pretending finding out compositional differences in lipids from atheroma plaques produced by different diseases, age and sex of the patients, but cause-effect relationship must be studied deeply.

${ }^{*}$ Corresponding author: Manuel León-Camacho, Lipid Characterization and Quality Department, Instituto de la Grasa (C.S.I.C.) Ctra Utrera km 1, Campus Universitario Pablo de Olavide, 41012 Seville-Spain. Avda, Padre García Tejero, Spain, Tel: ++34954611550; Fax: ++ 34 954616790; E-mail: mleon@cica.es

Received August 30, 2015; Accepted September 14, 2015; Published September 18,2015

Citation: Rivas MN, Ramírez IFP, Gallardo E, Peña JLG, Becerra JJ, et al. (2015) Characterization of Lipids in Femoral Atheroma from Diabetic Patients and Their Use as Clinical Descriptors. J Bioanal Biomed 7: 144-155. doi:10.4172/1948-593X.1000136

Copyright: ( 2015 Rivas MN, et al. This is an open-access article distributed under the terms of the Creative Commons Attribution License, which permits unrestricted use, distribution, and reproduction in any medium, provided the original author and source are credited. 
Citation: Rivas MN, Ramírez IFP, Gallardo E, Peña JLG, Becerra JJ, et al. (2015) Characterization of Lipids in Femoral Atheroma from Diabetic Patients and Their Use as Clinical Descriptors. J Bioanal Biomed 7: 144-155. doi:10.4172/1948-593X.1000136

\section{Experimental}

\section{Materials}

Hexane, fraction from petroleum, Multisolvent TM HPLC ACS grade supplied by Scharlau (Barcelona, Spain) was distilled through a fractionation column. Chloroform, methanol, diethyl ether, ammonia solution and 2-propanol for analysis grade were provided by Merck (Darmstadt, Germany). To identify the fatty acids and triacylglycerols, standards of each fatty acids purchased from SigmaAldrich (St. Louis, MO) were used: myristic (C14:0), palmitic (C16:0), palmitoleic (C16:1n-6), margaric (C17:0), cis-10-heptadecenoic acid (C17:1n-7), stearic (C18:0), elaidic (C18:1n-9 trans), oleic (C18:1n-9 cis), linoleic (C18:2n-6), arachidic (C20:0), linolenic (C18:3n-3) and cis-13-eicosenoic acid (C20:1n-9), trilinolein (LLL), triolein (OOO), tripalmitin (PPP) and tristearin (SSS). 1,3-dimyristin, oleic acid and 1-monopalmitin supplied by Sigma-Aldrich (St. Louis, MO) were also used as standards. Phospholipid standard solution (ref: P38171VL) containing phosphatidylethanolamine, phosphatidylcholine, phosphatidylinositol, phosphatidylserine and lysophosphatidylcholine was purchased from Supelco (Bellefonte, PA, USA). Triethylamine, phosphatidylethanolamine, phosphatidylcholine, phosphatidylinositol, phosphatidylserine, cardiolipin and sphingomyelin were purchased from Sigma Chemical Co. (St. Louis, MO, USA) and were used as standard. Chloroform and methanol, both LiChrosolv grade, were supplied by Merck (Darmstadt, Germany) and were used as HPLC solvents. All other materials were analytical grade.

\section{Samples}

Eighteen samples of femoral atheromas from eighteen written informed consenting human patients of older age subjected to surgical intervention at "Christus Muguerza" and "Regional de PEMEX "hospitals (Reynosa, Tamaulipas, Mexico) were used. Table 1 shows the general data and the identification code assigned to each sample. All patients were diagnosed with diabetes mellitus and hypertension. The protocol was approved by the Institutional Committee on Investigation in Humans. Besides, the protocol and patients' informed consent received institutional review board/independent ethics committee approval of "Christus Muguerza" and "Regional de PEMEX" Hospitals, and the study was conducted in accordance with the Declaration of Helsinki.

The femoral sections were cleaned under a dissection microscope, excised, and placed immediately in cold saline. The lipids were obtained from each sample by extraction with chloroform-methanol $(2: 1 \mathrm{v} / \mathrm{v})$ according to the procedure described by Folch et al. [26]. The samples were cut up into small pieces and homogenized before extraction with $3 \times 10 \mathrm{~mL}$ of solvent using an agitator. The solution was filtered and evaporated to dryness in a rotary evaporator at $30^{\circ} \mathrm{C}$ under reduced pressure.

\section{Isolation of different fractions by SPE}

The different lipid fractions were separated from atheromas by means of Solid Phase Extraction (SPE) according to the validated procedure previously described [27]. $200 \mathrm{mg}$ of the lipid extract was dissolved in $1.0 \mathrm{~mL}$ of hexane and was transferred into a silica gel bonded column, Supelclean LC-Si, $6 \mathrm{~mL}$ volume and $1 \mathrm{~g}$ sorbent (Supelco Bellefonte, PA, USA), which was conditioned with $10 \mathrm{~mL}$-hexane previously. A first fraction was eluted from column with $10 \mathrm{~mL}$-hexane: diethyl ether $(4: 1 \mathrm{v} / \mathrm{v})$, to collect the triacylglycerols. Then, a second fraction containing the free fatty acids, mono and diacylglycerols was eluted with $18 \mathrm{~mL}$ chloroform: 2-propanol $(2: 1 \mathrm{v} / \mathrm{v})$. Finally, a third fraction with the different phospholipid classes was recovered with $10 \mathrm{~mL}$ of methanol and afterwards $10 \mathrm{~mL}$ of methanol: chloroform: water $(5: 3: 2$ $\mathrm{v} / \mathrm{v} / \mathrm{v})$. The different fractions were evaporated to dryness in a rotary evaporator at $30^{\circ} \mathrm{C}$ under reduced pressure.

\section{tGC analysis of total fatty acids}

Fatty acid methyl esters (FAMEs) were analyzed by gas chromatography (GC). FAMEs were extracted with n-hexane after cold methylation with $2 \mathrm{~N} \mathrm{KOH}$ in methanol [28]. GC was performed with a Varian 3900 apparatus (Varian Co, Palo Alto, CA, USA) using a fused silica capillary HP 88 column $(100 \mathrm{~m} \times 0.25 \mathrm{~mm}, 0.25 \mu \mathrm{m}$ film thickness). The oven temperature was kept at $175^{\circ} \mathrm{C}$ for $13 \mathrm{~min}$ and was then raised to $205^{\circ} \mathrm{C}$ at a rate of $3.0^{\circ} \mathrm{C} \mathrm{min}^{-1}$ and held isothermally for $5.0 \mathrm{~min}$. The injector temperature was kept at $240^{\circ} \mathrm{C}$, while the detector

\begin{tabular}{|c|c|c|c|c|c|c|c|c|c|c|c|}
\hline Subjects & Sex & Age & $\begin{array}{l}\text { Stage of } \\
\text { atheroma }{ }^{1}\end{array}$ & $\begin{array}{c}\text { Femoral } \\
\text { artery }\end{array}$ & $\begin{array}{l}\text { Atheroma } \\
\text { (weight, g) }\end{array}$ & Diabetes & Hypertension & Dyslipidemia & $\begin{array}{l}\text { Metabolic } \\
\text { syndrome }\end{array}$ & $\begin{array}{l}\text { Heart } \\
\text { attack }\end{array}$ & $\begin{array}{l}\text { Renal } \\
\text { failure }\end{array}$ \\
\hline 1 & Male & 68 & $S$ & Right & 0.1825 & Yes & Yes & No & Yes & Yes & Yes \\
\hline 2 & Male & 80 & C & Right & 0.4285 & Yes & Yes & Yes & Yes & Yes & No \\
\hline 3 & Female & 73 & $S$ & Right & 0.2592 & Yes & Yes & Yes & Yes & Yes & No \\
\hline 4 & Female & 72 & SC & Left & 0.1786 & Yes & Yes & No & Yes & Yes & No \\
\hline 5 & Male & 86 & $\mathrm{C}$ & Right & 0.5544 & Yes & Yes & Yes & Yes & Yes & No \\
\hline 6 & Male & 71 & $\mathrm{MC}$ & Right & 0.5333 & Yes & Yes & Yes & Yes & Yes & Yes \\
\hline 7 & Male & 79 & SC & Right & 0.3463 & Yes & Yes & Yes & Yes & No & No \\
\hline 8 & Male & 68 & SC & Right & 0.2686 & Yes & Yes & No & Yes & Yes & Yes \\
\hline 9 & Female & 68 & $\mathrm{MC}$ & Right & 0.6065 & Yes & Yes & No & Yes & Yes & Yes \\
\hline 10 & Female & 61 & SC & Right & 0.4482 & Yes & Yes & Yes & Yes & No & No \\
\hline 11 & Male & 79 & $S$ & Left & 0.5919 & Yes & Yes & Yes & No & No & No \\
\hline 12 & Male & 58 & SC & Left & 0.6269 & Yes & Yes & No & Yes & No & No \\
\hline 13 & Male & 63 & $\mathrm{MC}$ & Right & 0.4434 & Yes & Yes & Yes & No & Yes & No \\
\hline 14 & Male & 74 & $S$ & Right & 0.5514 & Yes & Yes & Yes & No & No & No \\
\hline 15 & Male & 86 & $S$ & Right & 0.1743 & Yes & Yes & No & Yes & Yes & Yes \\
\hline 16 & Male & 71 & $S$ & Right & 0.3283 & Yes & Yes & Yes & Yes & No & No \\
\hline 17 & Male & 45 & $S$ & Left & 0.3934 & Yes & Yes & No & Yes & No & Yes \\
\hline 18 & Female & 44 & SC & Left & 0.5286 & Yes & Yes & No & Yes & No & No \\
\hline
\end{tabular}

Table 1: General data and identification code of analysed femoral atheroma Samples and medical records. 
temperature was $250^{\circ} \mathrm{C}$. Hydrogen $(131 \mathrm{kPa}$ inlet pressure) was used as carrier gas, while the make-up gas was nitrogen. Identification of fatty acids in the samples was carried out comparing retention times for standards and samples.

\section{GC analysis of triacylglycerols}

The residue of the first fraction collected by SPE method was redissolved in $0.5 \mathrm{~mL}$ of $\mathrm{n}$-hexane. Then, triacylglycerols were analyzed by GC [29] in a Varian 3800 (Varian Co, Palo Alto, CA, USA) using a fused silica capillary DB-17HT column $(30 \mathrm{~m} \times 0.32 \mathrm{~mm}$ I.D., 0.15 $\mu \mathrm{m}$ film thickness). The oven temperature was kept at $330^{\circ} \mathrm{C}$, and was then raised to $360^{\circ} \mathrm{C}$ at a rate of $2.0^{\circ} \mathrm{C} \mathrm{min}{ }^{-1}$ and held isothermally for $10 \mathrm{~min}$. The injector temperature was kept at $360^{\circ} \mathrm{C}$, while the detector temperature was $370^{\circ} \mathrm{C}$. Hydrogen $\left(5.3 \mathrm{~mL} \mathrm{~min}^{-1}\right.$ column constant flow) was used as carrier gas, while the make-up gas was nitrogen. The assignment of the chromatographic peaks was done by means of standards. The carbon number of the components associated with each peak group as well as the difference between the retention times of the triacylglycerols was calculated as described elsewhere [29].

\section{GC analysis of partial glycerides and free fatty acids}

The residue of the second fraction collected was re-dissolved in 500 $\mu \mathrm{L}$ of $\mathrm{n}$-hexane. Free fatty acids, mono and diacylglycerols form a part of fat polar fraction and, consequently, their analysis can be carried out following a methodology for suitable separation and quantification [30,31]. The residue was treated with $200 \mu \mathrm{L}$ of the silylating reagent and left at room temperature for 15 minutes.

One $\mu \mathrm{L}$ of the sylilated fraction was injected into the gas chromatographic system. The chromatographic analysis was performed using a Varian 3800 (Varian Co, Palo Alto, CA, USA) equipped with a split/splitless injector and a flame ionisation detector; a fused silica capillary DB-17HT column $(30 \mathrm{~m} \times 0,32 \mathrm{~mm}$ I.D., $0,15 \mu \mathrm{m}$ film thickness) and VARIAN 8100 automatic injector were used. Hydrogen was used as carrier gas a column constant flow of $4.0 \mathrm{~mL} \mathrm{~min}^{-1}$. Injector: split/split-less mode, split ratio 1:40, temperature $300^{\circ} \mathrm{C}$. The used liner for split mode injection in the 1079 Type Injector was a liner of type Gooseneck (ID=3.4 mm), which was deactivated and packed with Glass frit. The oven conditions were as follows: an initial temperature of $100^{\circ} \mathrm{C}$ and increased to $180^{\circ} \mathrm{C}$ at a rate of $15.0^{\circ} \mathrm{C} \mathrm{min}{ }^{-1}$ held for 5.33 min. Once the column reached $180^{\circ} \mathrm{C}$, the temperature was increased to $296^{\circ} \mathrm{C}$ at a rate of $7.0^{\circ} \mathrm{C} \mathrm{min}{ }^{-1}$ and held for $13.10 \mathrm{~min}$. While the detector temperature was $360^{\circ} \mathrm{C}$, air and hydrogen with flow rates of 300 and $30 \mathrm{~mL} \mathrm{~min}^{-1}$, respectively, were used for the detector, which had an auxiliary flow of $30 \mathrm{~mL} \mathrm{~min}^{-1}$ of nitrogen.

\section{HPLC analysis of phospholipid classes}

The residue of the last fraction collected was re-dissolved in 0.2 $\mathrm{mL}$ of chloroform. The different phospholipid classes were analyzed by HPLC according to the procedure previously described [27]. The HPLC system consisted on an Agilent (Palo Alto, CA, USA) 1100 liquid chromatograph, with a quaternary pump, an autosampler with variable injection volume ( 0 to $100 \mu \mathrm{L}$ ), a Peltier furnace and an evaporative light scattering detector Alltech ELSD 2000 (Deerfield, IL, USA). A Chemical station HP was used for controlling and monitoring the system. The separation was performed in a $100 \mathrm{x} 4.6 \mathrm{~mm}$ macropores size $2.1 \mu \mathrm{m}$ and mesopores size $13 \mathrm{~nm}$ Chromolith Performance Si column Merck (Darmstadt, Germany). The temperature of the column was held at $25^{\circ} \mathrm{C}$. A gradient elution was carried out using different ratios of solutions A (chloroform: methanol: ammonia solution, 80:19.5:0.5, v/v/v) and B (chloroform: methanol: triethylamine: water,
69.53:25.58:0.49:4.40, v/v/v/v). A better separation was obtained using the following gradient: from 0 to $5 \mathrm{~min}, \mathrm{~B}$ was increased from $0 \%$ to $40 \%$; from 5 to 7 min B was kept constant at $40 \%$; from 7 to $13 \mathrm{~min}$ B was increased from $40 \%$ to $100 \%$; from 13 to 20 min B was kept constant at $100 \%$; from 20 to $25 \mathrm{~min} \mathrm{~B}$ was decreased from $100 \%$ to $0 \%$; a time post-run of $5 \mathrm{~min}$ was done to equilibrate the column before the next injection. The flow rate was supported at $1 \mathrm{~mL} \mathrm{~min}^{-1}$ during $25 \mathrm{~min}$ and the injection volume was $50 \mu \mathrm{L}$. The evaporative light scattering detector used nitrogen as nebulising gas. The gas flow and the drift tube temperature were $1.5 \mathrm{~L} \mathrm{~min}^{-1}$ and $110^{\circ} \mathrm{C}$, respectively.

\section{Quantitative analysis and statistical treatment}

The peak area of each compound was used as analytical signal. The corresponding relative percentages of fatty acids, triacylglycerols, partial glycerides, free fatty acids and phospholipids were carried out according to the normalization area procedure assuming an equal factor response for any species. For quantification of the diacylglycerols, 1,3-dimyristin was used as internal standard. The internal standard was selected because no components eluted were found in this region. For quantification of the free fatty acids and monoacylglycerols, 1,3-dimyristin was used too, then the relative response factors were determined using solutions of 1.140 and $1.012 \mathrm{mg} \mathrm{mL}^{-1}$ of pure standard of oleic acid and 1-monopalmitin respectively, following the derivatization procedure described above. Relative response factors determined for free fatty acids and monoacylglycerols were previously described in the literature [31].

The quantification of individual triacylglycerol was carried out by using trimiristin as internal standard assuming an equal factor response for any species. The quantification for each different phospholipid classes was carried out by a calibration curve for each phospholipid class injecting standard solutions of the different species identified. Duplicate analysis was performed for each sample.

In order to study the recovery and reproducibility (R) of the present method for triacylglycerols, free fatty acids, mono- and diacylglycerols (first and second fractions of SPE method), a complementary experiment was conducted. Recovery data were calculated by comparing the results of different compounds determination added to a blank of fat matrix with those obtained from the GC direct analysis of different standards that were analyzed in the same way. Eight replicates were utilized in each case. For the determination of repeatability, the replicates were analyzed on different days in the same laboratory. Concerning to glycerides and free fatty acids, similar results were obtained than in the method using diol columns [31]. Isomerisation of diacylglycerols was not found using silica bounded columns. The recovery and reproducibility for the phospholipid fraction (third fraction) was previously studied [27].

The limit of detection (LOD) of the method was reported as the signal to noise ratio of 3 for blank samples. The limit of quantification (LOQ) of the different compounds was reported as the signal to noise ratio of 10 [32]. Eight independent determinations were made. LOD and LOQ were the same than in previous works $[27,31]$.

Sixteen fatty acids, seventeen triacylglycerols, eleven diacylglycerols being each of them as 1,2- and 1,3-isomers, two free fatty acids, 1 -monoolein and sevent phospholipid classes were identified. The different compounds were considered as chemical descriptors. A data matrix, whose rows are the samples and whose columns are the variables, was built. Each element of this matrix $x_{i j}$ corresponds to the content of each compounds $\mathrm{j}$ for the sample $\mathrm{i}$.

Statistical analysis based on non-parametric techniques was used, 
including the Kolmogorov-Smirnov-Lilliefors test, which was used to evaluate the normality of each variable included in the study. Since the data distribution was not normal, non-parametric tests were applied. The Kruskal-Wallis test was used to find out significant differences for the variables with three levels. This test is a one way analysis of variance by ranks, i.e., the nonparametric equivalence of one way ANOVA. Kruskal-Wallis test calculates the $\mathrm{H}$ parameter for comparison with the chi-squared distribution for $n-1$ degrees of freedom and $p=0.05$, where $\mathrm{n}$ is the number of groups being considered. When significant differences are detected, a post hoc comparison highlights the pairs of groups responsible for those differences. The Mann-Whitney $U$ test was used to determinate the differences between two levels of the same variable. So, the differences in composition of atheroma have been studied according to age, sex, or the corresponding disease such as dyslipidemia, heart attack, metabolic syndrome and renal failure. This test is the nonparametric alternative to the t-Student test for independent means. The statistical parameter $U$ was obtained for each compound, and the respective $\mathrm{z}$ values were calculated to be compared with the $\mathrm{z}$ value in the normalized standard distribution.

Linear discriminant analysis (LDA) compute linear combinations of the data to form discriminant functions (DFs), aiming for the separation of categories by the minimization of the within-class and between-class ratio of the sum of squares. The model can be constructed through a stepwise approach, which selects only the most discriminating variables. In this way, LDA can be used to reduce the number of chemical descriptors to be used in the characterization of classes. Statistical analysis and Patter Recognition calculations were made using the statistical package STATISTICA 8.0 from Statsoft (Tulsa, OK, USA)

\section{Results and Discussion}

\section{Identification of components}

Table 2 shows the median and standard deviation values, in relative percentages, of the total fatty acids analyzed.

The most abundant fatty acid in atheromas from diabetic human patients was $\mathrm{C} 18: \ln 9 \mathrm{c}$, with an average value of $23.74 \%$. The other major fatty acids were C18:2n6c and C16:0, with mean values of 18.25 and $17.64 \%$ respectively. On the other hand, the minor ones founded were $\mathrm{C} 17: 0, \mathrm{C} 17: 1 \mathrm{n} 7 \mathrm{c}, \mathrm{C} 18: 2 \mathrm{n} 9 \mathrm{t} 12 \mathrm{t}$ and $\mathrm{C} 18: 2 \mathrm{n} 9 \mathrm{c} 12 \mathrm{t}$, with mean values lower than $1 \%$. Higher percentages of C16:0, C18:1n9c, C22:0, $\mathrm{C} 18: 2 \mathrm{n} 9 \mathrm{t} 12 \mathrm{t}$ and $\mathrm{C} 18: 2 \mathrm{n} 9 \mathrm{t} 12 \mathrm{c}$ where found in females, while C14:0 presented a higher abundance in males. Attending to the age of the patients, the C14:0 acid was higher in patients which age was $<70$ and C18:2n9t12t was more abundant in the older patients $(>70)$. The patients with dyslipidemia showed a higher level in C18:2n9t12t. Patients with metabolic syndrome presented a lower percentage in C18:2n9t12t and $\mathrm{C} 18: 2 \mathrm{n} 9 \mathrm{t} 12 \mathrm{c}$ fatty acids. Higher levels of C18:1n9c and C18:2n6c were found with the heart attack. When the renal failure was involved, lower percentages of $\mathrm{C} 18: 1 \mathrm{n} 9 \mathrm{c}$ were observed while $\mathrm{C} 18: 2 \mathrm{n} 6 \mathrm{c}$ presented the opposite trend.

In Table 3, the median and standard deviation values, in relative percentages and in $\mathrm{mg} \mathrm{g}^{-1}$ of lipids, of the different triacylglycerols detected in the atheroma samples are shown. The most abundant triacylglycerol in these samples is the MOP $\left(29.87 \%, 34155.6 \mathrm{mg} \mathrm{g}^{-1}\right.$ of lipids), followed by PPP (15.28\%, $17544.8 \mathrm{mg} \mathrm{g}^{-1}$ of lipids), POO (14.28\%, $20576.09 \mathrm{mg} \mathrm{g}^{-1}$ of lipids) and PLO (11.91\%, $13457.53 \mathrm{mg} \mathrm{g}^{-1}$ of lipids). The minor species of these compounds were PPS (0.39\%, 419.34 $\mathrm{mg} \mathrm{g}^{-1}$ of lipids), SOS $\left(0.21 \%, 298.34 \mathrm{mg} \mathrm{g}^{-1}\right.$ of lipids) and PSS $(0.18 \%$,
$287.64 \mathrm{mg} \mathrm{g}^{-1}$ of lipids). MOP and PLO were more abundant in females, while POO and SOL presented higher concentration in males. Higher levels of POO were found in older patients and when the dyllipidemia was present. PLO was lower in patients that suffered a heart attack, while PPP and MOP presented higher levels in those patients, and the same is observed in the case of the renal failure.

The values for means and standard deviations of 1,2-diacylglycerols and 1,3-diacylglycerols are presented in Tables 4 and 5, respectively, as a relative percentage of total diacylglycerols and as $\mathrm{mg} \mathrm{g}^{-1}$ of lipids. The most abundant of 1,2-diacylglycerols was 1,2-PPo (16.61\%, $5030.89 \mathrm{mg}$ $\mathrm{g}^{-1}$ of lipids), followed by 1,2-OS (9.22\%, $3438.06 \mathrm{mg} \mathrm{g}^{-1}$ of lipids), while $1,2-\mathrm{MO}$ was the least abundant $\left(1.43 \%, 626.95 \mathrm{mg} \mathrm{g}^{-1}\right.$ of lipids). On the other hand, $1,3-\mathrm{OO}\left(5.67 \%, 1547.16 \mathrm{mg} \mathrm{g}^{-1}\right.$ of lipids) and $1,3-\mathrm{MO}$ $\left(5.37 \%, 1490.1 \mathrm{mg} \mathrm{g}^{-1}\right.$ of lipids) were the major 1,3-isomers, whereas 1,3$\mathrm{MO}\left(0.35 \%, 247.25 \mathrm{mg} \mathrm{g}^{-1}\right.$ of lipids) and 1,3-OPo (0.2\%, $40.34 \mathrm{mg} \mathrm{g}^{-1}$ of lipids) showed the lowest concentrations. It can be observed that total 1,2-diacylglycerols are more abundant than total 1,3-diacylglycerols.

Means and standard deviations for free fatty acids (\% and $\mathrm{mg} \mathrm{g}^{-1}$ of lipids) and 1-monoolein are shown in Table 6. Oleic acid was almost the double than palmitic acid. The amount of 1-monoolein was smaller than those found for the free fatty acids, but higher than the minor diacylglycerols (1,3-MO and 1,3-OPo).

In Table 7, the values for means and standard deviations of phospholipid classes are shown as a relative percentage of total phospholipids and as $\mathrm{mg} \mathrm{g}^{-1}$ of lipids. Sphingomyelin is the major phospholipid class $\left(55.95 \%, 103.45 \mathrm{mg} \mathrm{g}^{-1}\right.$ of lipids), followed by phosphatidylcholine $\left(22.47 \%, 34.26 \mathrm{mg} \mathrm{g}^{-1}\right.$ of lipids), phosphatidylserine showing the lowest concentration $\left(1.66 \%, 2.66 \mathrm{mg} \mathrm{g}^{-1}\right.$ of lipids). The highest standard deviations are observed in SPH. Atheromas from females showed higher concentrations of all phospholipids in general. Higher concentrations were observed for the dyslipidemia cases, except for the PS. However, in the cases of heart attacks, the levels of phospholipids were lower. The highest concentrations of PE, PI, PC, SPH and LPC were found in atheromas of patients that no presented renal failure.

\section{Use of these compounds as clinical descriptors}

To study the influence of the different identified compounds in the atheromas from diabetic human patients according to sex, age (less than 70 years old and higher than 70 years old), dyslipidemia, metabolic syndrome, heart attack and renal failure, and determine significant differences, the Mann-Whitney $U$ test was performed. The statistical parameter $U$ was obtained for each compound and the respective $\mathrm{z}$-values were calculated for comparison with the $\mathrm{z}$-value in the normalized standard distribution for $95 \%$ confidence $(\mathrm{z}=1.96)$.

The results of Mann-Whitney test are presented in Tables S1-S6 for every family of compounds, showing the effects of sex, age (less than 70 years old and higher than 70 years old), dyslipidemia, metabolic syndrome, heart attack and renal failure on the composition of every family of compounds.

In Table S1, for the case of total fatty acids, it can be observed that the obtained $\mathrm{z}$-values were higher than the critical one for C16:0 when sex was considered, this showing the greatest differences with $z$-values higher than the critical one (2.367). The other fatty acids presented $\mathrm{z}$-values of up to 1.235 (in absolute value), lower than the critical one. Age and dyslipidemia produced significant differences in the percentages of $\mathrm{C} 18: 2 \mathrm{n} 9 \mathrm{t} 12 \mathrm{t}$, absolute $\mathrm{z}$-values being 2.278 and 2.545 respectively. The presence or not of metabolic syndrome also affected to 


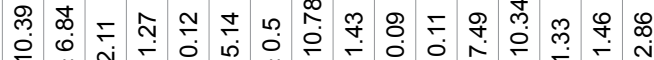

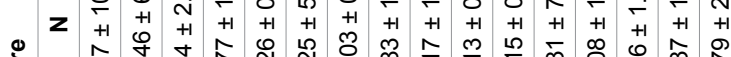

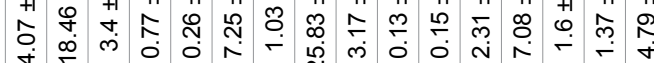

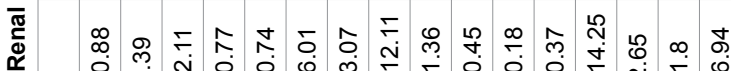

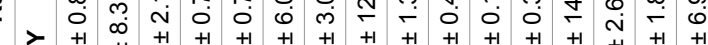

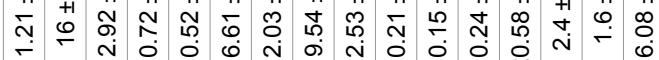
হ

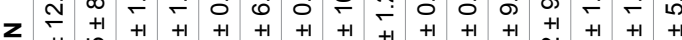

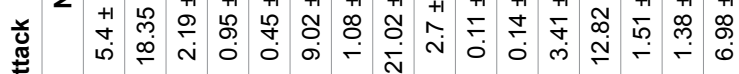

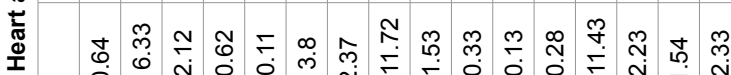

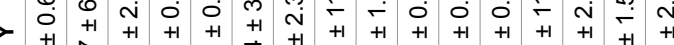

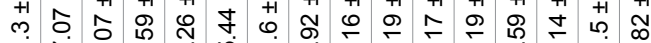

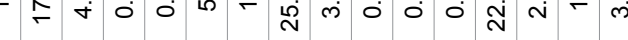

ஸे $/$ S

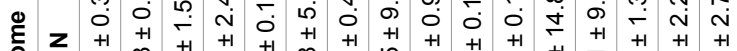

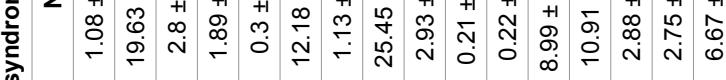

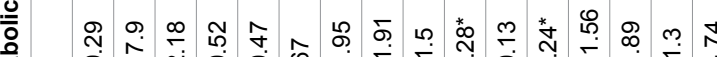

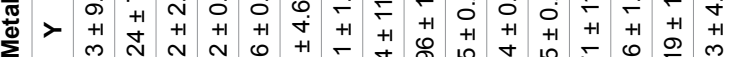

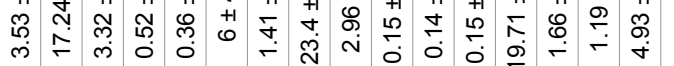

$\bar{\tau}$ స

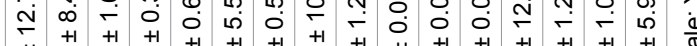

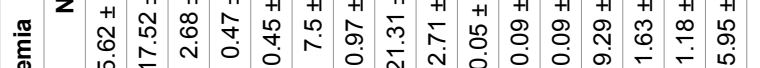

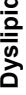

\%

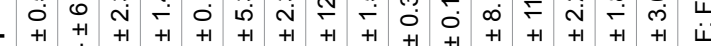

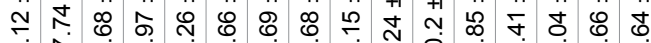
$\therefore$ -

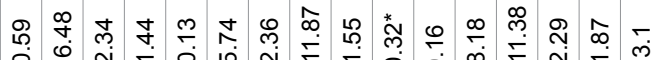

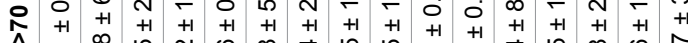

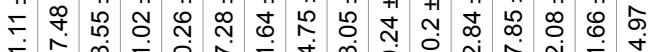
$\stackrel{9}{8}$

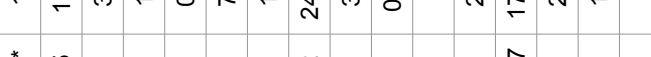

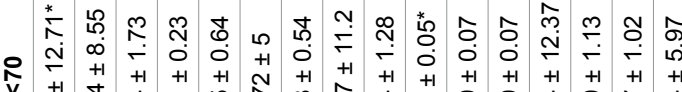

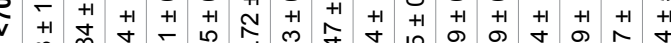

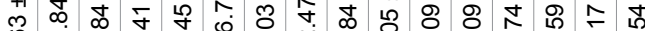

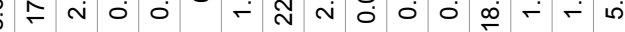

ڤ

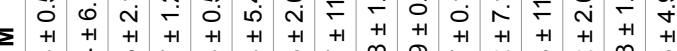

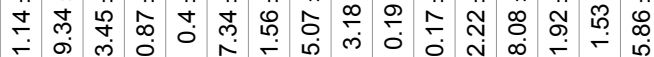
œ

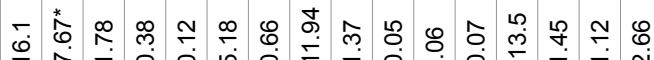

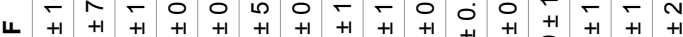
స̦ N n

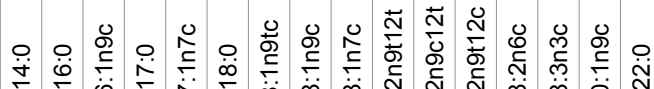

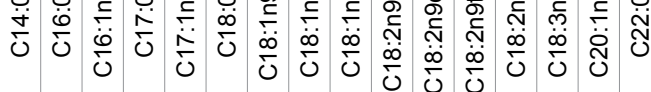

ริ $\therefore$ 일

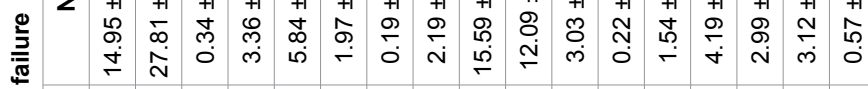

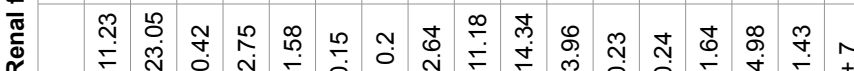

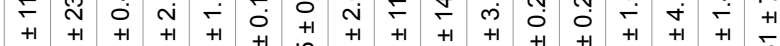
先 மீ œ

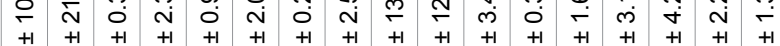

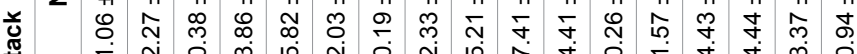

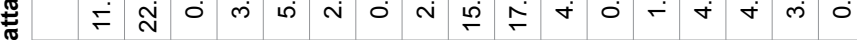

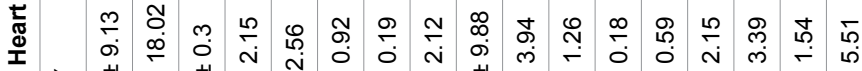

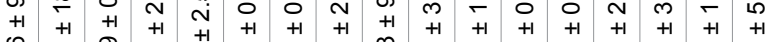
\&

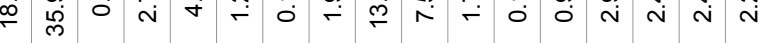

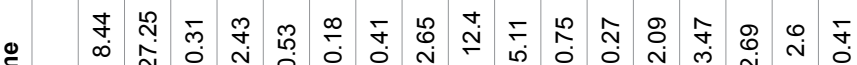

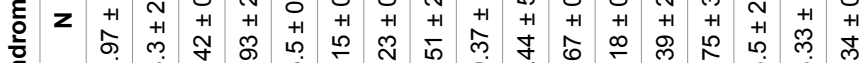

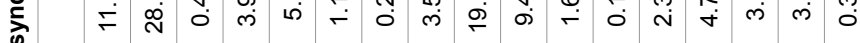

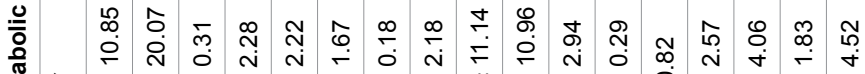

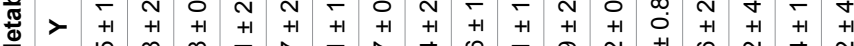

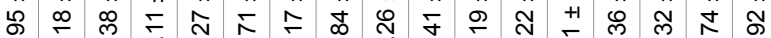
மீ f. N

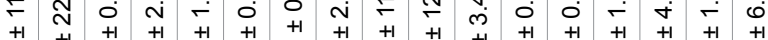

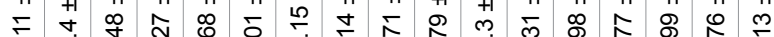

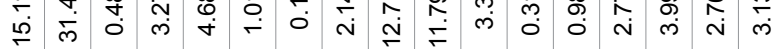

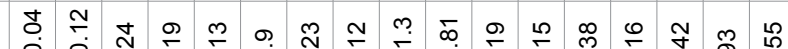

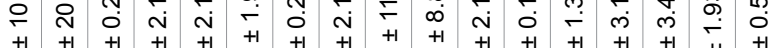

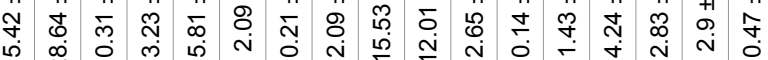

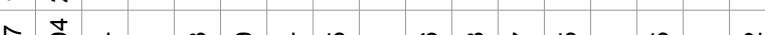

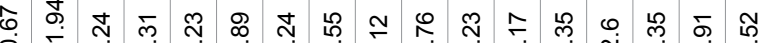

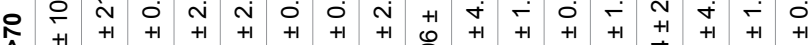
更 \%

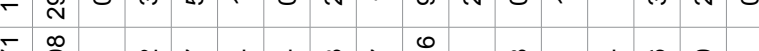
స

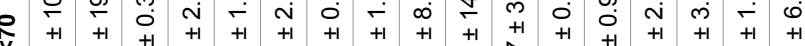
டீ மூ

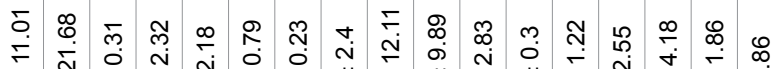

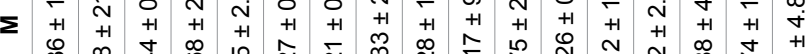

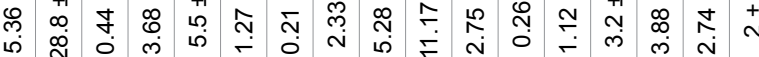
$\stackrel{\times}{\infty}$ ڤ్

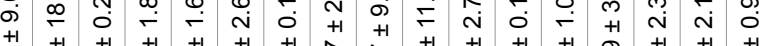

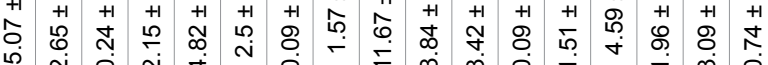
$\therefore$ ले

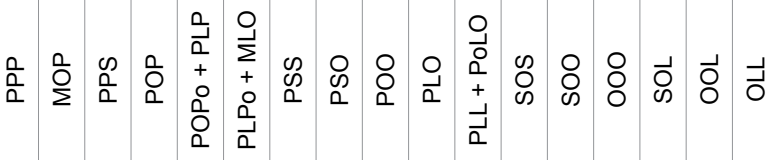




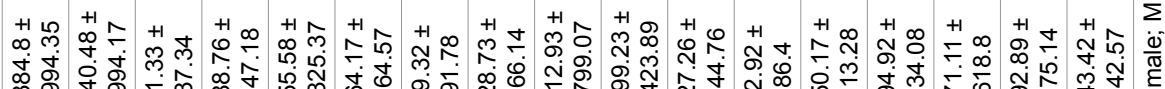

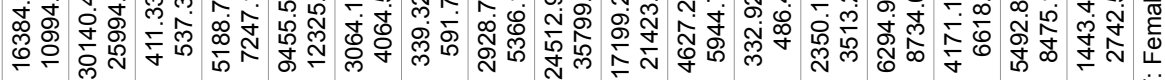

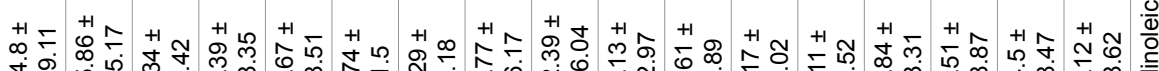

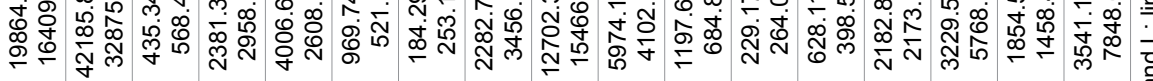

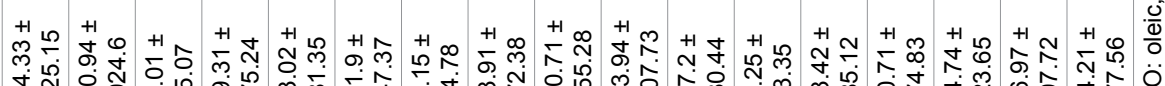

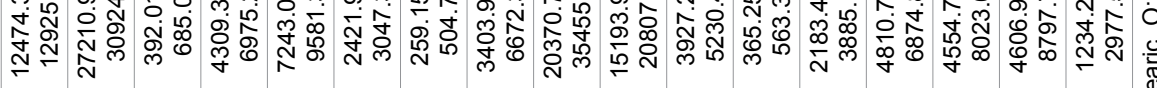
每

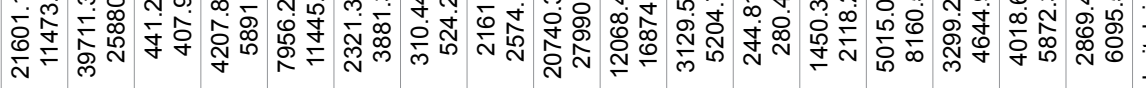

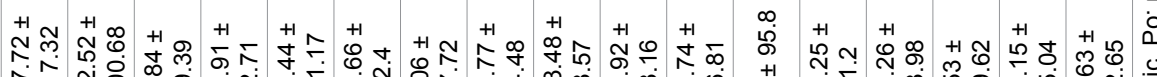

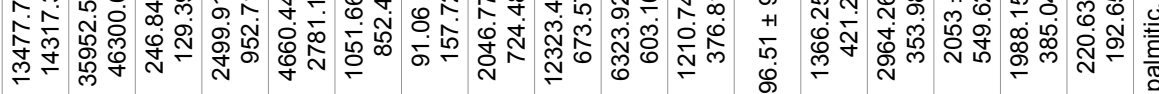

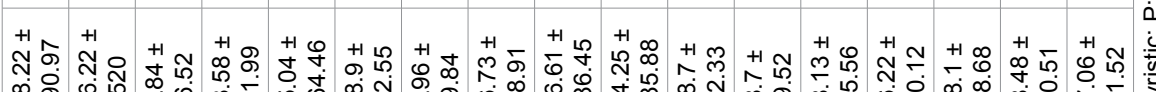

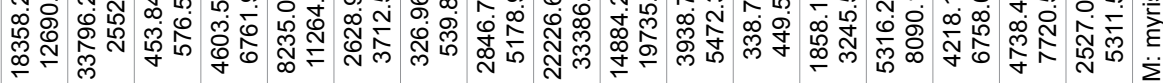

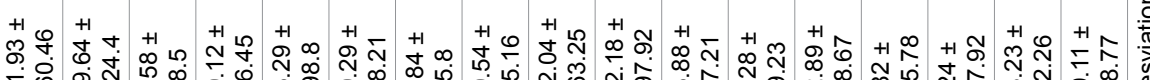

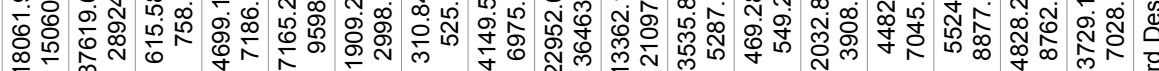

$+\frac{1}{+}+1=0$

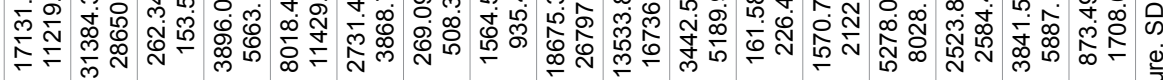

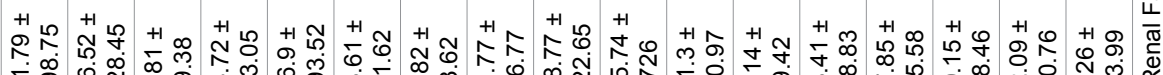

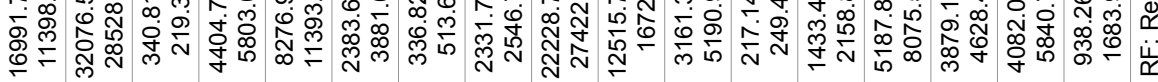

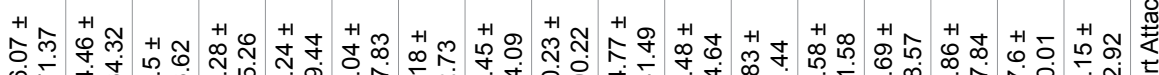

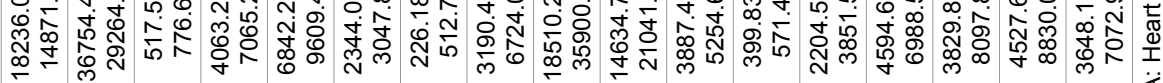

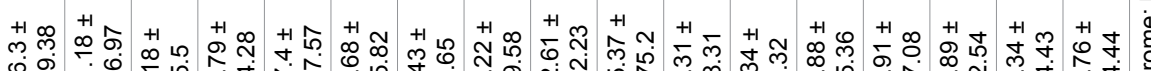

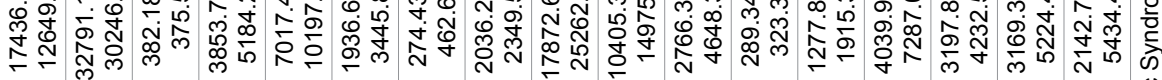

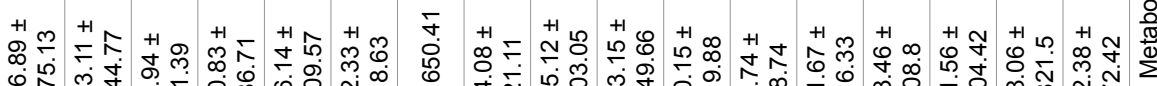

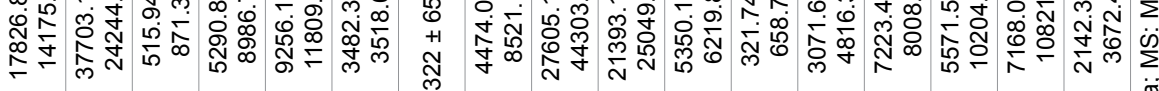

\begin{tabular}{|c|c|c|c|c|c|c|c|c|c|c|c|c|c|c|c|c|}
\hline$\frac{0}{0}$ & $\frac{0}{2}$ & $\begin{array}{l}\infty \\
\frac{0}{2}\end{array}$ & $\begin{array}{l}0 \\
0 \\
\alpha\end{array}$ & $\begin{array}{l}0 \\
0 \\
0 \\
+ \\
0 \\
0 \\
0 \\
0\end{array}$ & 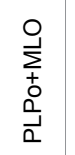 & $\begin{array}{l}\infty \\
\infty \\
0\end{array}$ & $\begin{array}{l}0 \\
\text { on } \\
0\end{array}$ & ঃ & $\stackrel{\circ}{\vec{a}}$ & 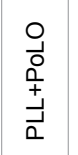 & $\begin{array}{l}\text { D } \\
\text { on }\end{array}$ & ০ & ৪ & $\overrightarrow{0}$ & $\overrightarrow{\mathrm{o}}$ & $\vec{\partial}$ \\
\hline
\end{tabular}




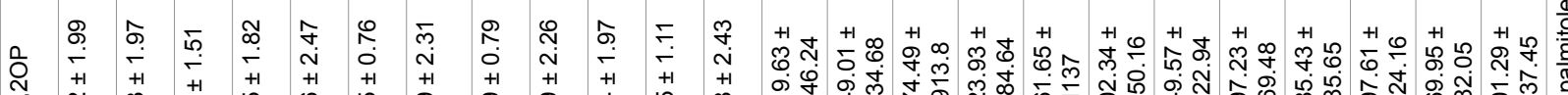

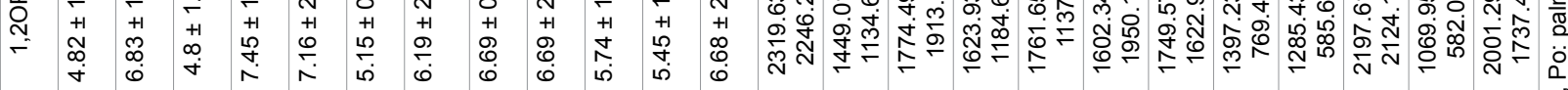

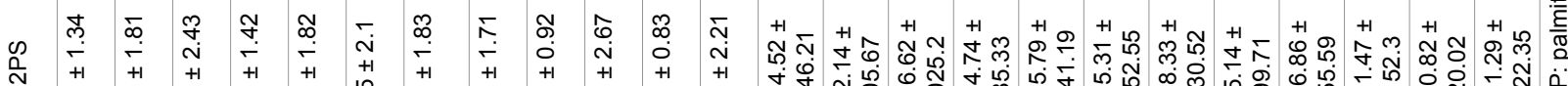

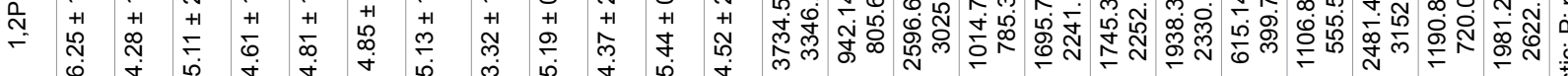

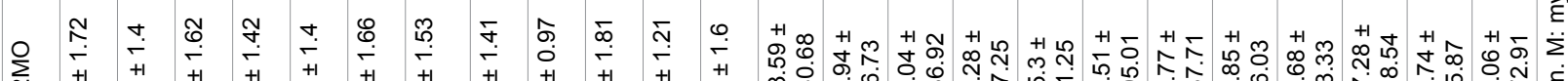

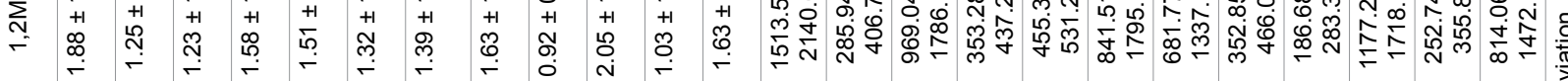

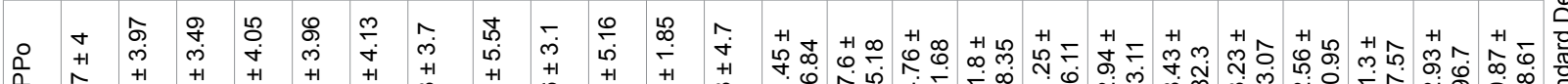

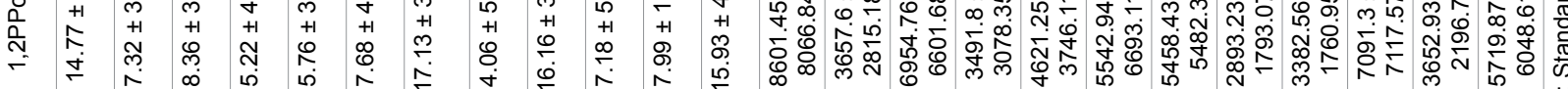

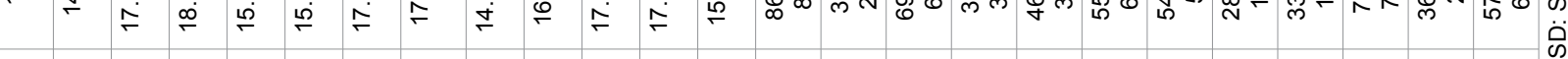

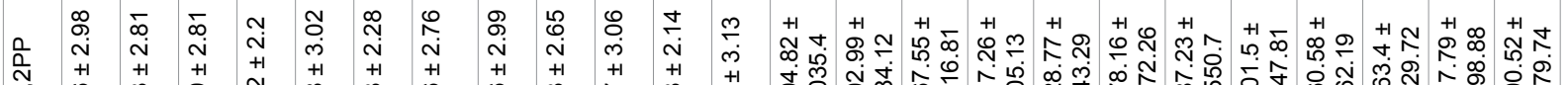

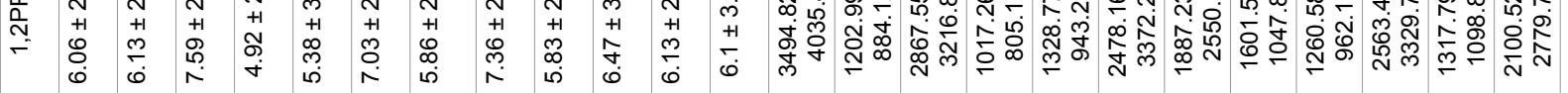

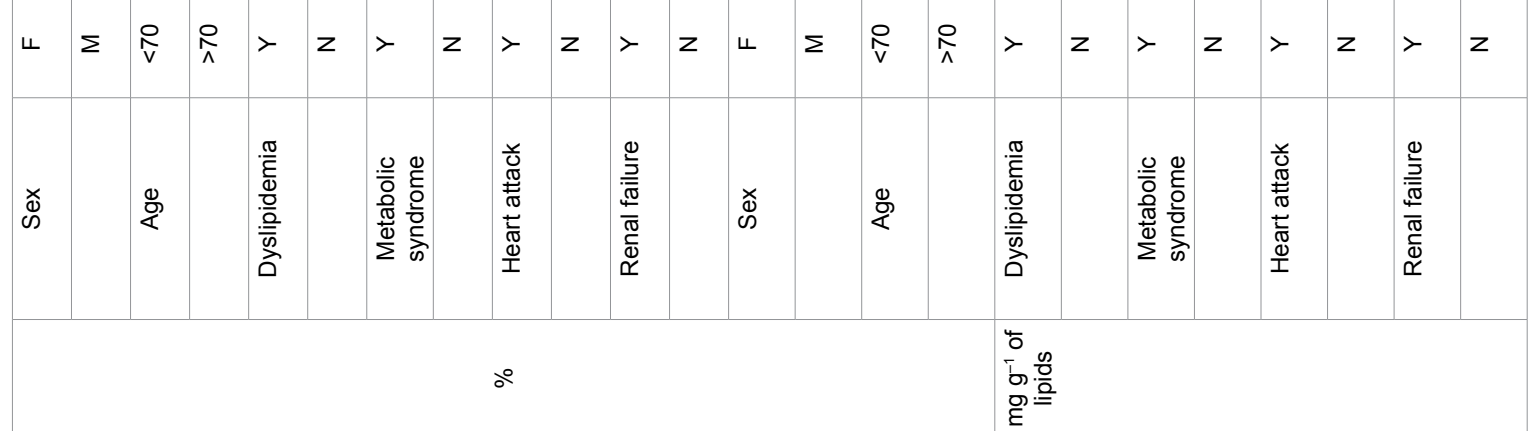




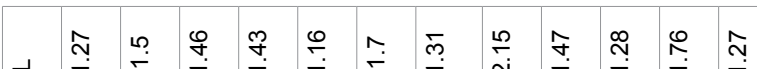

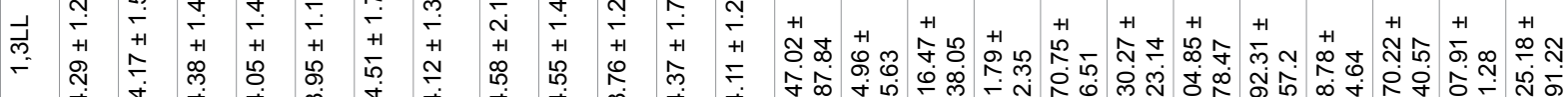

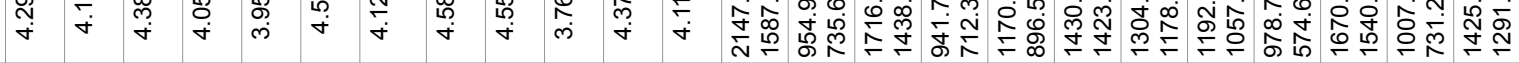

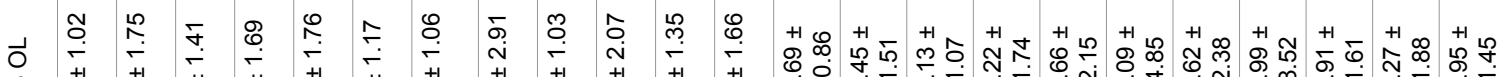

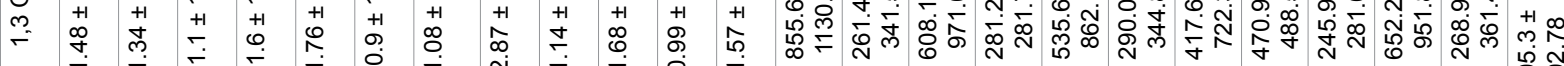

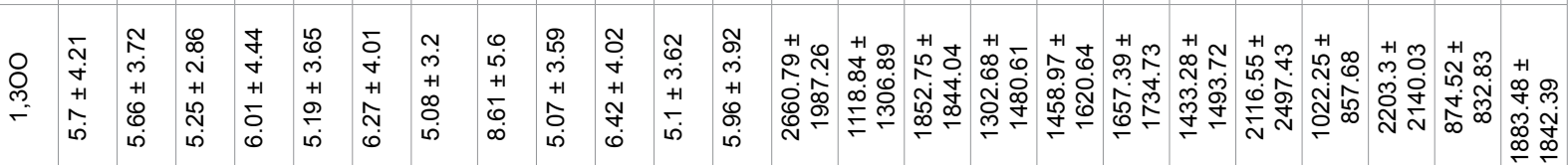

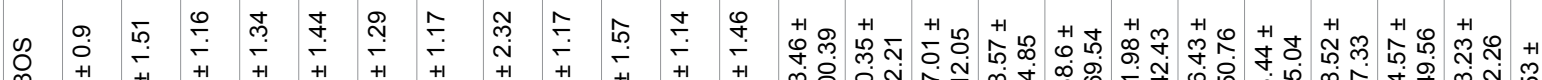

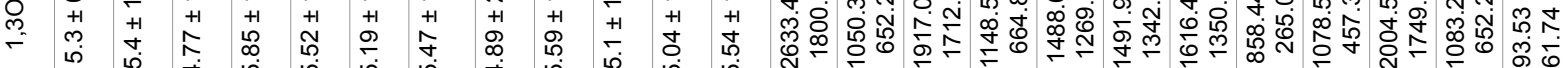

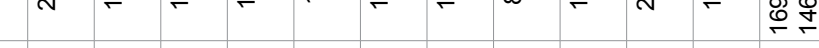

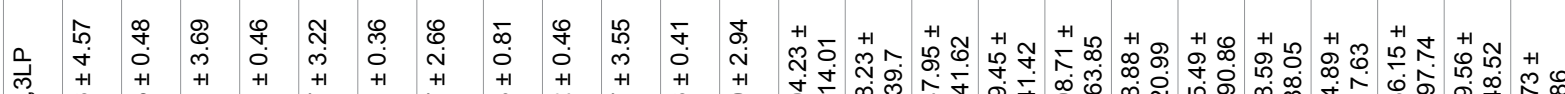

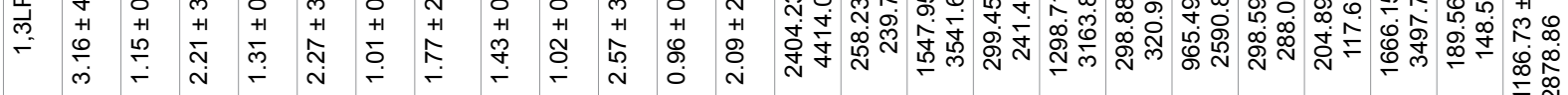

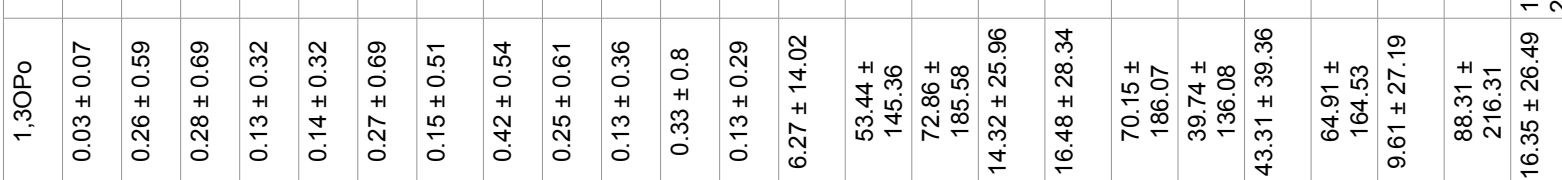

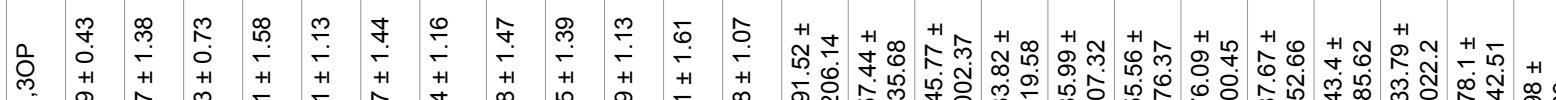

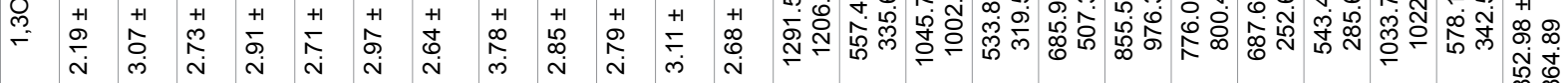

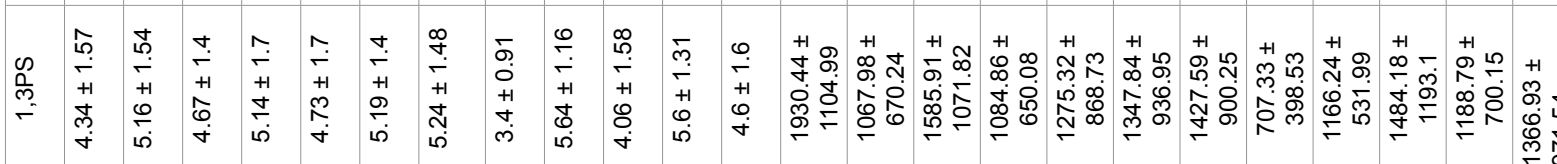

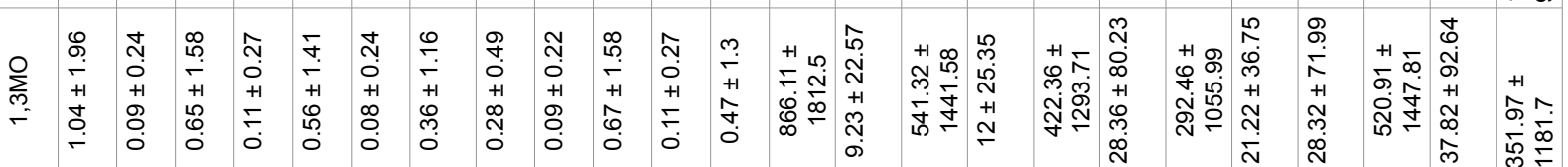

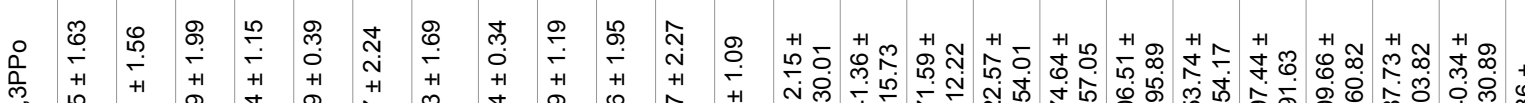

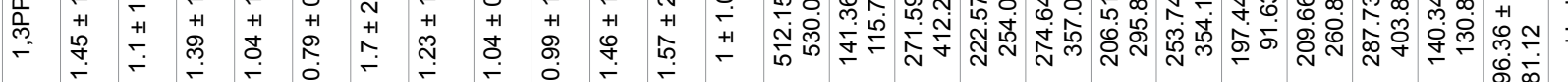

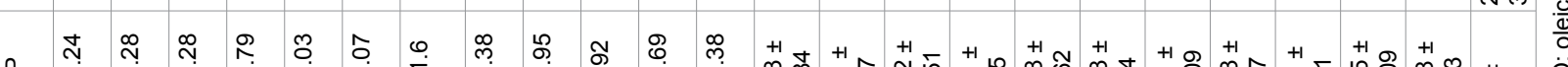

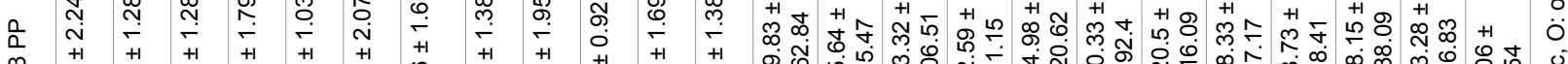

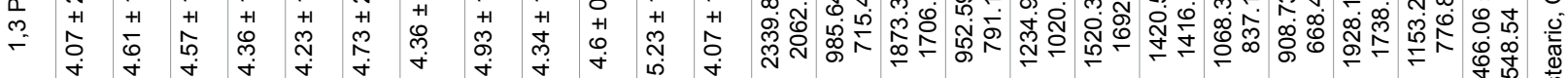

\begin{tabular}{|c|c|c|c|c|c|c|c|c|c|c|c|c|c|c|c|c|c|c|c|c|c|}
\hline$\dot{\square}$ & $\stackrel{+}{+}$ & $\because$ & $\because$ & $\stackrel{\neg}{\Im}$ & $\because$ & $\dot{+}$ & $\because \ddot{\square}$ & $\dot{\nabla}$ & i̊ & $\ddot{+}$ & in & & 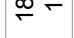 & & $\digamma$ & - & & & $\digamma$ & ${ }^{-}$ & 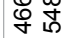 \\
\hline ४ & $\Sigma$ & $\stackrel{\imath}{v}$ & $\stackrel{R}{\wedge}$ & $>$ & $z$ & $>$ & $z$ & $z$ & $>$ & $z$ & ч & $\Sigma$ & 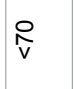 & $\stackrel{i}{\Lambda}$ & $>$ & $z$ & $>$ & $z$ & $z$ & $>$ & $z$ \\
\hline ふ્ & & 迶 & & 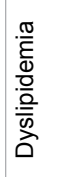 & & 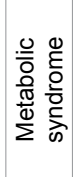 & 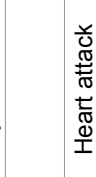 & & 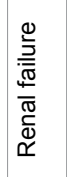 & & 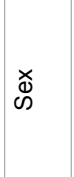 & & $\stackrel{\infty}{\&}$ & & 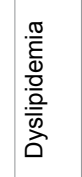 & & 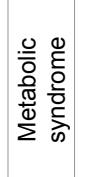 & 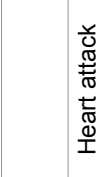 & & 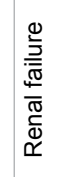 & \\
\hline
\end{tabular}


Citation: Rivas MN, Ramírez IFP, Gallardo E, Peña JLG, Becerra JJ, et al. (2015) Characterization of Lipids in Femoral Atheroma from Diabetic Patients and Their Use as Clinical Descriptors. J Bioanal Biomed 7: 144-155. doi:10.4172/1948-593X.1000136

\begin{tabular}{|c|c|c|c|c|c|c|}
\hline & & & $\%$ & & $\mathrm{mg} \mathrm{g}^{-1}$ of lipids & \\
\hline & & Palmitic acid & Oleic acid & Palmitic acid & Oleic acid & 1-Monoolein \\
\hline \multirow[t]{2}{*}{ Sex } & $\mathrm{F}$ & $39.36 \pm 5.92$ & $60.64 \pm 5.92$ & $526.71 \pm 633.62$ & $760.88 \pm 900.48$ & $74.91 \pm 106.18$ \\
\hline & $\mathrm{M}$ & $39.14 \pm 5.01$ & $60.86 \pm 5.01$ & $1749.08 \pm 1399.61$ & $2871.88 \pm 2413.56$ & $510.27 \pm 697.43$ \\
\hline \multirow[t]{2}{*}{ Age } & $<70$ & $38.06 \pm 5.43$ & $61.94 \pm 5.43$ & $1790.29 \pm 1344.86$ & $2828.06 \pm 2205.56$ & $324.23 \pm 256.99$ \\
\hline & $>70$ & $40.11 \pm 4.9$ & $59.89 \pm 4.9$ & $1104.93 \pm 1323.31$ & $1851.43 \pm 2379.26$ & $441.42 \pm 819.42$ \\
\hline \multirow[t]{2}{*}{ Dyslipidemia } & $\mathrm{Y}$ & $38.34 \pm 4.97$ & $61.66 \pm 4.97$ & $1381.29 \pm 1464.27$ & $2455.09 \pm 2747.54$ & $234.54 \pm 254.11$ \\
\hline & $\mathrm{N}$ & $40.27 \pm 5.38$ & $59.73 \pm 5.38$ & $1444.84 \pm 1264.57$ & $2073.49 \pm 1717.59$ & $582.84 \pm 882.05$ \\
\hline \multirow[t]{2}{*}{ Metabolic syndrome } & $\mathrm{Y}$ & $39.75 \pm 5.29$ & $60.25 \pm 5.29$ & $1172.59 \pm 1268.37$ & $1796.42 \pm 1975.44$ & $365.91 \pm 676.51$ \\
\hline & $\mathrm{N}$ & $36.45 \pm 3.31$ & $63.55 \pm 3.31$ & $2594.27 \pm 1211$ & $4730.8 \pm 2557.29$ & $506.45 \pm 234.13$ \\
\hline \multirow[t]{2}{*}{ Heart attack } & $\mathrm{Y}$ & $40.59 \pm 5.8$ & $59.41 \pm 5.8$ & $884.18 \pm 1097.62$ & $1447.34 \pm 2099.39$ & $428.73 \pm 829.98$ \\
\hline & $\mathrm{N}$ & $37.46 \pm 3.69$ & $62.54 \pm 3.69$ & $2066.23 \pm 1386.45$ & $3333.17 \pm 2196.3$ & $340.09 \pm 217.69$ \\
\hline \multirow[t]{2}{*}{ Renal failure } & $\mathrm{Y}$ & $38.57 \pm 4.97$ & $61.43 \pm 4.97$ & $994.38 \pm 824.8$ & $1537.23 \pm 1300.09$ & $634.18 \pm 1024.22$ \\
\hline & $\mathrm{N}$ & $39.51 \pm 5.34$ & $60.49 \pm 5.34$ & $1617.11 \pm 1524.23$ & $2659.61 \pm 2624.17$ & $266.92 \pm 266.58$ \\
\hline
\end{tabular}

Table 6: Means and standard deviations by groups of free fatty acids ( $\%$ and $\mathrm{mg} \mathrm{g}^{-1}$ of lipids) and 1-monoolein ( $\mathrm{mg} \mathrm{g}^{-1}$ of lipids)

\begin{tabular}{|c|c|c|c|c|c|c|c|c|c|}
\hline & & & CL & PE & PI & PS & PC & SPH & LPC \\
\hline \multirow[t]{12}{*}{$\%$} & Sex & $\mathrm{F}$ & $6.63 \pm 1.94$ & $5.19 \pm 4.94$ & $3.27 \pm 1.69$ & $1.9 \pm 2.62$ & $20.59 \pm 7.63$ & $58.92 \pm 11.01$ & $3.5 \pm 1.48$ \\
\hline & & $M$ & $8.17 \pm 6.23$ & $5.68 \pm 4.01$ & $2.58 \pm 2.1$ & $1.57 \pm 2.5$ & $23.2 \pm 7.15$ & $54.81 \pm 11.57$ & $3.99 \pm 1.68$ \\
\hline & Age & $<70$ & $7.8 \pm 5.97$ & $5.31 \pm 4.07$ & $2.9 \pm 1.89$ & $1.45 \pm 2.7$ & $20.01 \pm 6.87$ & $58.28 \pm 8.55$ & $4.26 \pm 1.66$ \\
\hline & & $>70$ & $7.7 \pm 5.16$ & $5.74 \pm 4.4$ & $2.67 \pm 2.13$ & $1.84 \pm 2.38$ & $24.44 \pm 7.1$ & $54.08 \pm 13.18$ & $3.53 \pm 1.56$ \\
\hline & Dyslipidemia & $\mathrm{Y}$ & $7.97 \pm 4.46$ & $6.29 \pm 4.91$ & $2.72 \pm 1.99$ & $1.84 \pm 2.38$ & $24.83 \pm 8.05$ & $53.03 \pm 13.9$ & $3.34 \pm 1.53$ \\
\hline & & $\mathrm{N}$ & $7.46 \pm 6.64$ & $4.62 \pm 2.96$ & $2.84 \pm 2.07$ & $1.45 \pm 2.7$ & $19.53 \pm 4.84$ & $59.61 \pm 5.61$ & $4.5 \pm 1.53$ \\
\hline & $\begin{array}{l}\text { Metabolic } \\
\text { syndrome }\end{array}$ & $\mathrm{Y}$ & $7.81 \pm 5.6$ & $4.95 \pm 3.31$ & $2.94 \pm 1.86$ & $2 \pm 2.57$ & $22.58 \pm 5.8$ & $55.54 \pm 8.6$ & $4.17 \pm 1.37$ \\
\hline & & $\mathrm{N}$ & $7.4 \pm 4.96$ & $8.5 \pm 7.28$ & $1.93 \pm 2.74$ & $0 \pm 0$ & $21.91 \pm 14.14$ & $58 \pm 23.47$ & $2.27 \pm 2.02$ \\
\hline & Heart attack & $Y$ & $8.73 \pm 6.16$ & $4.2 \pm 2.71$ & $3.03 \pm 1.75$ & $2.53 \pm 2.73$ & $20.58 \pm 4.53$ & $56.95 \pm 6.36$ & $3.98 \pm 0.94$ \\
\hline & & $\mathrm{N}$ & $6.51 \pm 4.23$ & $7.23 \pm 5.13$ & $2.44 \pm 2.29$ & $0.58 \pm 1.63$ & $24.83 \pm 9.31$ & $54.7 \pm 15.88$ & $3.71 \pm 2.24$ \\
\hline & Renal failure & $\mathrm{Y}$ & $7.92 \pm 7.85$ & $4.28 \pm 3.42$ & $2.61 \pm 2.39$ & $1.93 \pm 3.01$ & $20.72 \pm 5.27$ & $57.96 \pm 5.12$ & $4.58 \pm 1.36$ \\
\hline & & $\mathrm{N}$ & $7.65 \pm 4.05$ & $6.18 \pm 4.45$ & $2.85 \pm 1.84$ & $1.53 \pm 2.27$ & $23.35 \pm 8.01$ & $54.94 \pm 13.43$ & $3.5 \pm 1.64$ \\
\hline \multirow{12}{*}{$\begin{array}{l}\mathrm{mg} \mathrm{g}^{-1} \text { of } \\
\text { lipids }\end{array}$} & Sex & $\mathrm{F}$ & $14.77 \pm 8.51$ & $16.45 \pm 26.67$ & $9.26 \pm 11.02$ & $3.74 \pm 5.69$ & $54.77 \pm 59.17$ & $129.17 \pm 58.67$ & $7.31 \pm 3.48$ \\
\hline & & $M$ & $9.38 \pm 7.81$ & $4.5 \pm 3.05$ & $2.71 \pm 1.61$ & $2.24 \pm 3.88$ & $26.37 \pm 25.04$ & $93.55 \pm 161.1$ & $5.05 \pm 5.68$ \\
\hline & Age & $<70$ & $12.69 \pm 9.82$ & $10.83 \pm 21.55$ & $6.34 \pm 9.27$ & $2.72 \pm 5.15$ & $36.49 \pm 51.2$ & $90.7 \pm 70$ & $5.46 \pm 3.82$ \\
\hline & & $>70$ & $9.42 \pm 6.7$ & $5.4 \pm 3.16$ & $3.08 \pm 1.59$ & $2.6 \pm 3.84$ & $32.47 \pm 25.85$ & $113.64 \pm 180.48$ & $5.86 \pm 6.26$ \\
\hline & Dyslipidemia & $\mathrm{Y}$ & $11.54 \pm 8.56$ & $11.14 \pm 18.74$ & $5.58 \pm 8.28$ & $2.6 \pm 3.84$ & $45.88 \pm 47.75$ & $129.03 \pm 180.96$ & $6.39 \pm 6.16$ \\
\hline & & $\mathrm{N}$ & $10.05 \pm 8.08$ & $3.66 \pm 2.97$ & $3.22 \pm 2.07$ & $2.72 \pm 5.15$ & $19.73 \pm 11.21$ & $71.47 \pm 53.9$ & $4.79 \pm 3.81$ \\
\hline & $\begin{array}{l}\text { Metabolic } \\
\text { syndrome }\end{array}$ & $\mathrm{Y}$ & $11.29 \pm 7.91$ & $8.17 \pm 15.59$ & $4.87 \pm 6.79$ & $3.19 \pm 4.57$ & $33.98 \pm 37.05$ & $80.53 \pm 56.75$ & $5.16 \pm 2.95$ \\
\hline & & $\mathrm{N}$ & $8.78 \pm 10.86$ & $6.03 \pm 5.44$ & $2.83 \pm 2.77$ & $0 \pm 0$ & $35.64 \pm 51.04$ & $218.04 \pm 344.55$ & $8.28 \pm 12.43$ \\
\hline & Heart attack & $\mathrm{Y}$ & $10.35 \pm 7.15$ & $3.74 \pm 1.86$ & $2.96 \pm 0.82$ & $3.67 \pm 4.55$ & $23.39 \pm 9.41$ & $68.42 \pm 40.4$ & $4.65 \pm 2.91$ \\
\hline & & $\mathrm{N}$ & $11.53 \pm 9.72$ & $12.9 \pm 20.93$ & $6.5 \pm 9.34$ & $1.39 \pm 3.95$ & $47.85 \pm 54.75$ & $147.23 \pm 202.66$ & $6.96 \pm 7.12$ \\
\hline & Renal failure & $\mathrm{Y}$ & $11.1 \pm 9.48$ & $2.46 \pm 1.89$ & $2.66 \pm 1.5$ & $3.63 \pm 5.76$ & $20.06 \pm 13.41$ & $66.98 \pm 57.85$ & $4.63 \pm 4.12$ \\
\hline & & $\mathrm{N}$ & $10.76 \pm 7.85$ & $10.49 \pm 17.04$ & $5.47 \pm 7.56$ & $2.17 \pm 3.61$ & $41.36 \pm 44.44$ & $121.68 \pm 165.44$ & $6.21 \pm 5.72$ \\
\hline
\end{tabular}

CL: Cardiolipin; PE: phosphatidylethanolamine; PI: phosphatidylinositol; PS: phosphatidylserine; PC: phosphatidylcholine; SPH: sphingomyelin; LPC: lysophosphatidylcholine F: Female; M: Male; Y: Yes; N: No.

Table 7: Means and standard desviations by groups of phospholipid clases (\% and $\mathrm{mg} \mathrm{g}^{-1}$ of lipids)

the C18:2n9t12t and C18:2n9t12c acid percentages, absolute $\mathrm{z}$-values being 1.965 and 2.078 respectively. Heart attack and renal failure did not cause any effect in fatty acid composition of human atheromas.

Sex, age (less than 70 years old and higher than 70 years old), dyslipidemia, metabolic syndrome, heart attack and renal failure did not produce any effect on the concentrations of triacylglycerols $\left(\mathrm{mg} \mathrm{g}^{-1}\right.$ of lipids) (Table S2). However, dyslipidemia and renal failure produce significance differences in relative percentage of PLPo+MLO, absolute 
Citation: Rivas MN, Ramírez IFP, Gallardo E, Peña JLG, Becerra JJ, et al. (2015) Characterization of Lipids in Femoral Atheroma from Diabetic Patients and Their Use as Clinical Descriptors. J Bioanal Biomed 7: 144-155. doi:10.4172/1948-593X.1000136

z-values being 2.75 and 2.34 respectively. Besides, the SOO percentage was affected by renal failure ( 2.15 absolute $z$-value).

Like in the case of triacylglycerols, none of the variables mentioned above caused significant differences in the concentrations of diacylglycerols ( $\mathrm{mg} \mathrm{g}^{-1}$ of lipids) (Tables S3 and S4). On the other hand, sex produced significant differences on percentages of 1,2-PS, 1,2-OPo and 1,2-LL diacylglycerols, absolute z-values being 2.12, 2.51 and 2.32 respectively, while percentages of $1,2-\mathrm{OP}$ were affected by age of the patient and the presence of dyslipidemia ( 2.84 and 2.67 absolute $\mathrm{z}$-values, respectively). For the case of 1,3-diacylglycerols, only the heart attack caused significant differences in percentages of 1,3-PS, showing an absolute $z$-value of 2.13 .

As well, the effect of stage of atheroma (soft, slightly calcified, moderately calcified, calcified) has been studied applying a KruskalWallis test. The results showed that there are only significant differences $(\mathrm{p}<0.05)$ between moderately calcified and soft for percentage relative of 1,3-LP, being the mean value highest in moderately calcified.

No effect of any variables on free fatty acid percentages or amounts ( $\mathrm{mg} \mathrm{g}^{-1}$ of lipids) was observed (Table S5). In the case of 1-monoolein, the sex of the patient was the only variable that produced significant differences in its concentration ( $\mathrm{mg} \mathrm{g}^{-1}$ of lipids), showing an absolute $\mathrm{z}$-value of 2.22 .

According to the results obtained for the Mann-Whitney $\mathrm{U}$ test obtained for phospholipid classes, only the concentration of sphingomyelin ( $\mathrm{mg} \mathrm{g}^{-1}$ of lipids) of atheroma plaques was affected by the sex of the patient (Table S6), absolute $\mathrm{z}$-value being 2.12. No significant differences were found for the relative percentages of these compounds.

The following step in our analysis was to apply procedures of supervised pattern recognition in order to use the studied compounds as clinical descriptors. Accordingly, Linear Discriminant Analysis [33] was applied to the data set also, to obtain suitable classification rules for the patients. The corresponding discriminant functions were calculated for every family of compound (fatty acids, triacylglycerols, diacylglycerols, monoacylglycerol, free fatty acids and phospholipids) as linear combinations of the chemical descriptors. The criterion used for feature selection was the forward stepwise approach. In a first run, all the variables are present in the model; in each step the variable with least discriminant power, according to the Wilks' l statistic test [34], is rejected. In our case, the grouping variables were sex, age (less than 70 years old and higher than 70 years old), dyslipidemia, metabolic syndrome, heart attack, renal failure and stage of atheroma. None of the studied compounds showed total discrimination for age, renal failure and metabolic syndrome cases.

Referent to differentiation between female and male, just the relative percentages of diacylglycerols and triacylglycerols, as set or separately, had discriminant power. The selected variables were 1,2-PS, 1,2-LL, 1,2PPo, 1,2-OP, 1,3-OO, 1,3-OPo, OOL, PSS and PLPo+MLO. The equation of the obtained discrimination function is show in Table S7 of the supplementary electronic material, with a recognition ability of $100 \%$. Figure 1 shows the patients distribution in the space of the two obtained discriminant functions. Male and female patients appear completely separated.

The amounts of diacylglycerols ( $\mathrm{mg} \mathrm{g}^{-1}$ of lipids) were the only compounds with total discriminant power in the cases of dyslipidemia. The selected variables were 1,2-OPo, 1,2-OO, 1,2-OP, 1,3-PP, 1,3-OL, 1,3-PS and 1,2-PP. The equation of the obtained discrimination function is show in Table S8 of the supplementary electronic material, with a recognition ability of $100 \%$. Figure 2 shows the patients distribution in the space of the two obtained discriminant functions. The patients with and without dyslipidemia appear completely separated.

In the case of heart attack, the selected variables were relative percentage of 1,3-PS, 1,2-OL, 1,3-LP, 1,2-PS, 1,2-PPo, 1,2-OPo, 1,3$\mathrm{OL}$ and 1,2-OS. The equation of the obtained discrimination function is show in Table S9 of the supplementary electronic material, with a recognition ability of $100 \%$. Figure 3 shows the patients distribution in the space of the two obtained discriminant functions. The patients with and without heart attack appear completely separated.

Finally, a $100 \%$ classification performance was obtained for the five considered stage of atheroma (soft, slightly calcified, moderately calcified, calcified) using the relative percentages of diacylglycerols 1,2 OP, 1,2-LL, 1,2-LP, 1,3-OO, 1,2-OL, 1,3-PP, 1,3-PPo, 1,3-OS, 1,2-OS, 1,2OO and 1,3-PS. The equation of the obtained discrimination function (DF) is shown in Table S10 of the supplementary electronic material and the distribution in the space of the two obtained discriminant functions in Figure 4, the five stages of atheroma appearing completely separated.

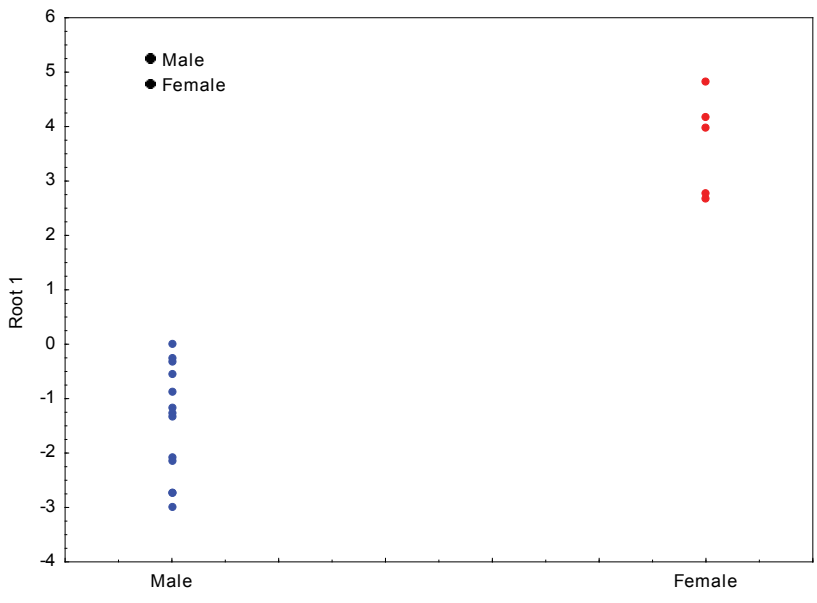

Figure 1: Scatterplot of the canonical scores corresponding to male and female patients.

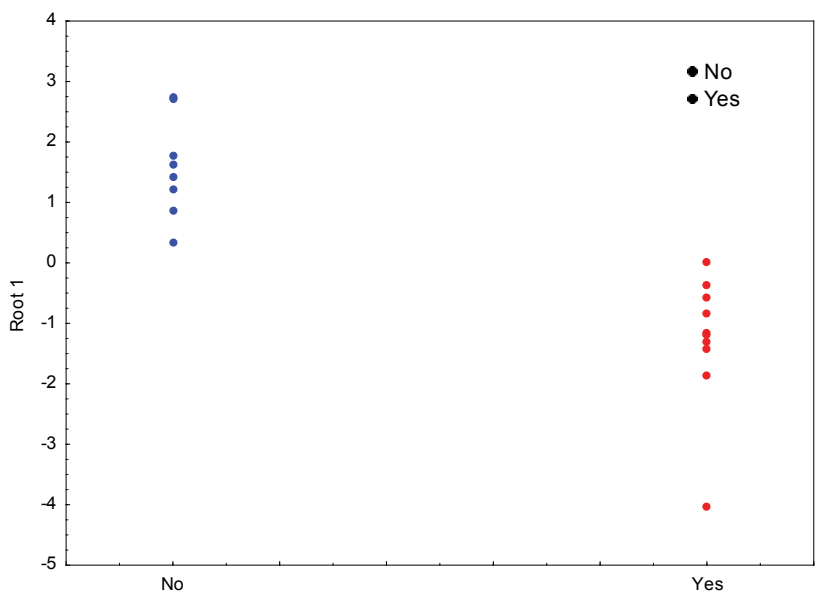

Figure 2: Scatterplot of the canonical scores corresponding to patients with and without dyslipidemia. 
Citation: Rivas MN, Ramírez IFP, Gallardo E, Peña JLG, Becerra JJ, et al. (2015) Characterization of Lipids in Femoral Atheroma from Diabetic Patients and Their Use as Clinical Descriptors. J Bioanal Biomed 7: 144-155. doi:10.4172/1948-593X.1000136

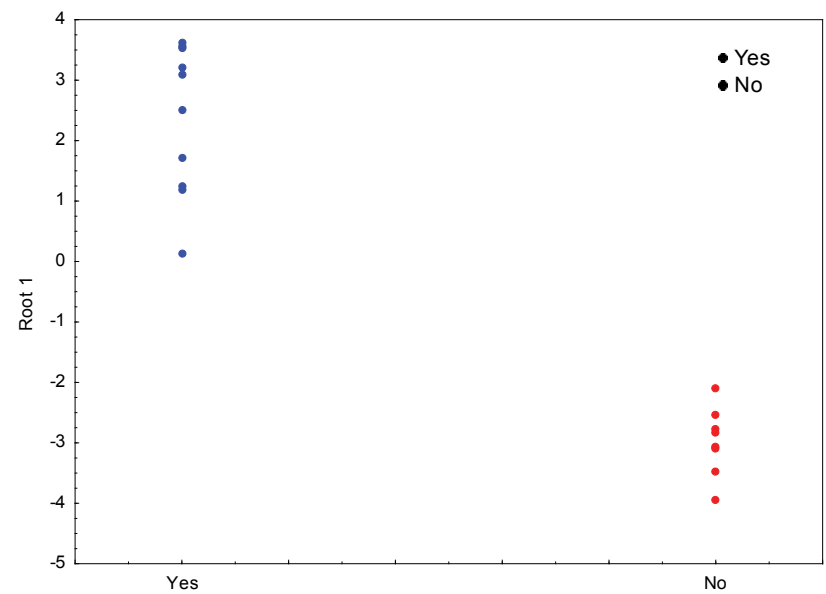

Figure 3: Scatterplot of the canonical scores corresponding to patients with and without heart attack.
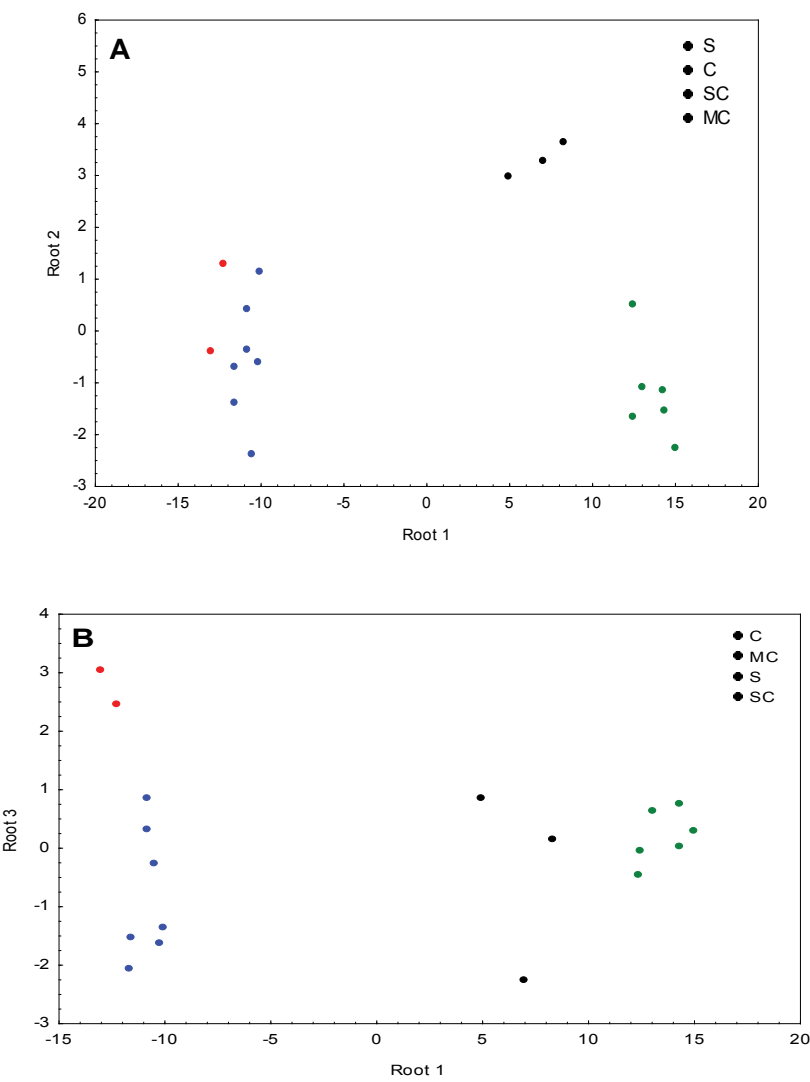

Figure 4: Scatterplot of the canonical scores corresponding to the stage of ateroma S:Soft; SC: Slightly calcified; MC: Moderately calcified; C: Calcified. A: Root 1 vs Root 2; B: Root 1 vs Root 3.

\section{Conclusion}

In this work, a new SPE method has been developed to characterize the different lipid fractions of atheroma plaque from diabetic human patients. A study of the discriminating power of the different compounds characterized has been performed in order to stablish then as clinical descriptor. Forward stepwise, a LDA was then applied for each family of compounds, only diacylglycerols and triacylglycerols gave models with a total classification when sex, dyslipidemia, heart attack and stage of atheroma from patients were considered.

\section{Acknowledgement}

The authors are grateful to "Christus Muguerza" and "Regional de PEMEX "hospitals (Reynosa, Tamaulipas, Mexico) for the collaboration and given help and especially to Dr. José Alberto Ramirez de León for her help and advising.

\section{References}

1. Tabas I (2010) Macrophage death and defective inflammation resolution in atherosclerosis. Nat Rev Immunol 10: 36-46.

2. OMS (2008) Investigaciones para una cobertura sanitaria universa (Clasificación NLM: W 84.6).

3. Frayn K, Stanner S (2005) Cardiovascular Disease: Diet, Nutrition and Emerging Risk Factors. Blackwell Publishing, England.

4. Henry PD1, Chen $\mathrm{CH}$ (1993) Inflammatory mechanisms of atheroma formation Influence of fluid mechanics and lipid-derived inflammatory mediators. Am J Hypertens 6: 328S-334S

5. Tsimikas S, Glass C, Steinberg D, Witztum JL (2004) Molecular basis of cardiovascular disease: A Companion to Braunwald's Heart Disease, WB Saunders Co, Philadelphia.

6. Libby P (2002) Inflammation in atherosclerosis. Nature 420: 868-874.

7. Viles-Gonzalez JF1, Anand SX, Valdiviezo C, Zafar MU, Hutter R, et al. (2004) Update in atherothrombotic disease. Mt Sinai J Med 71: 197-208.

8. Peng S, Guo W, Morrisett JD, Johnstone MT, Hamilton JA (2000) Quantification of cholesteryl esters in human and rabbit atherosclerotic plaques by magicangle spinning (13)C-NMR. Arterioscler Thromb Vasc Biol 20: 2682-2688.

9. Weissberg $P$ (1999) Mechanisms modifying atherosclerotic disease - from lipids to vascular biology. Atherosclerosis 147 Suppl 1: S3-10.

10. de Korte CL, Pasterkamp G, van der Steen AF, Woutman HA, Bom N (2000) Characterization of plaque components with intravascular ultrasound elastography in human femoral and coronary arteries in vitro. Circulation 102 617-623.

11. Marinello E, Setacci C, Giubbolini M, Cinci G, Frosi B, et al. (2003) Lipid composition in atheromatous plaque: evaluation of the lipid three-phase percentage. Life Sci 72: 2689-2694.

12. McGrath LT, Elliott RJ (1990) Lipid analysis and fatty acid profiles of individual arterial atherosclerotic plaques. Anal Biochem 187: 273-276.

13. Römer TJ, Brennan JF 3rd, Schut TC, Wolthuis R, van den Hoogen RC, et al. (1998) Raman spectroscopy for quantifying cholesterol in intact coronary artery wall. Atherosclerosis 141: 117-124.

14. Accad M, Smith SJ, Newland DL, Sanan DA, King LE Jr, et al. (2000) Massive xanthomatosis and altered composition of atherosclerotic lesions in hyperlipidemic mice lacking acyl CoA:cholesterol acyltransferase 1. J Clin Invest 105: 711-719.

15. Cohn JS, Marcoux C, Davignon J (1999) Detection, quantification, and characterization of potentially atherogenic triglyceride-rich remnant lipoproteins. Arterioscler Thromb Vasc Biol 19: 2474-2486.

16. Guo W, Morrisett JD, Lawrie GM, DeBakey ME, Hamilton JA (1998) Identification of different lipid phases and calcium phosphate deposits in human carotid artery plaques by MAS NMR spectroscopy. Magn Reson Med 39: 184-189.

17. Kingsbury KJ, Brett C, Stovold R, Chapman A, Anderson J, et al. (1974) Abnormal fatty acid composition and human atherosclerosis. Postgrad Med J 50: $425-440$

18. Piotrowski JJ, Shah S, Alexander JJ (1996) Mature human atherosclerotic plaque contains peroxidized phosphatidylcholine as a major lipid peroxide. Life Sci 58: 735-740.

19. Orlandi A, Marcellini M, Spagnoli LG (2000) Aging influences development and progression of early aortic atherosclerotic lesions in cholesterol-fed rabbits. Arterioscler Thromb Vasc Biol 20: 1123-1136.

20. Seeger JM, Barratt E, Lawson GA, Klingman N (1995) The relationship between carotid plaque composition, plaque morphology, and neurologic symptoms. J Surg Res 58: 330-336. 
Citation: Rivas MN, Ramírez IFP, Gallardo E, Peña JLG, Becerra JJ, et al. (2015) Characterization of Lipids in Femoral Atheroma from Diabetic Patients and Their Use as Clinical Descriptors. J Bioanal Biomed 7: 144-155. doi:10.4172/1948-593X.1000136

21. Weissberg $P$ (1999) Mechanisms modifying atherosclerotic disease - from lipids to vascular biology. Atherosclerosis 147 Suppl 1: S3-10.

22. Lee S, Birukov KG, Romanoski CE, Springstead JR, Lusis AJ, et al. (2012) Role of phospholipid oxidation products in atherosclerosis. Circ Res 111: 778-799.

23. Marinello E, Setacci C, Giubbolini M, Cinci G, Frosi B, et al. (2003) Lipid composition in atheromatous plaque: evaluation of the lipid three-phase percentage. Life Sci 72: 2689-2694.

24. Felton CV Crook D, Davies MJ, Oliver MF (1997) Relation of plaque lipid composition and morphology to the stability of human aortic plaques. Arterioscler Thromb Vasc Biol 17: 1337-1345.

25. Ekroos K, Jänis M, Tarasov K, Hurme R, Laaksonen R (2010) Lipidomics: a too for studies of atherosclerosis. Curr Atheroscler Rep 12: 273-281.

26. Folch J, Lees M, Stanley GHS (1957) A simple method for the isolation and purification of total lipids from animal tissues. J Biol Chem 226: 497-509.

27. Narváez-Rivas M, Gallardo E, Rios JJ, León-Camacho M (2011) A new high-performance liquid chromatographic method with evaporative light scattering detector for the analysis of phospholipids. Application to Iberian pig subcutaneous fat. J Chrom A 1218: 3453-3458.

28. Narváez-Rivas M, León-Camacho M, Vicario IM (2009) Fatty acid and triacylglycerol composition of the subcutaneous fat from Iberian pigs fattened on the traditional feed: "Montanera". Effect of anatomical location and length of feeding, Grasas y Aceites 60: 238-247.

29. Narváez-Rivas M, Gallardo E, León-Camacho M (2013) Changes in the fatty acid and triacylglycerol profiles in the subcutaneous fat of Iberian ham during the dry-curing process. Food Res Int 54: 213-222.

30. Verleyen T, Verhe R, Garcia L, Dewettinck K, Huyghebaert A, et al. (2001) Gas chromatographic characterization of vegetable oil deodorization distillate. J Chromatogr A 921: 277-285.

31. Narváez-Rivas M, Vicario IM, Constante EG, León-Camacho M (2007) Changes in the concentrations of free fatty acid, monoacylglycerol, and diacylglycerol in the subcutaneous fat of Iberian ham during the dry-curing process. J Agric Food Chem 55: 10953-10961.

32. Thompson M, Ellison SLR, Wood R (2002) Harmonized guidelines for singlelaboratory validation of methods of analysis (IUPAC Technical Report). Pure Appl Chem 74: 835-855.

33. Coomans D, Massart DL, Kaufman L (1979) Optimization by statistical linear discriminant analysis in analytical chemistry. Anal Chim Acta 112: 97-122.

34. Gardine WP (1997) Statistical analysis methods for chemistry. Royal Society of Chemistry, Cambridge. 